\title{
Impact of Extreme Meteorological Events on Ozone in the Pearl River Delta, China
}

\author{
Xiaohua Lin, Zibing Yuan*, Leifeng Yang, Huihong Luo, Wenshi Li \\ School of Environment and Energy, South China University of Technology, Guangzhou 510006, China
}

\begin{abstract}
Along with rapid economic development in the Pearl River Delta (PRD) region of China for the past two decades, ozone $\left(\mathrm{O}_{3}\right)$ pollution has deteriorated significantly. Extreme meteorological events (EMEs), including heat wave (HW), atmospheric stagnation (AS), and temperature inversion (TI), exert significant impacts on $\mathrm{O}_{3}$. Base on observational $\mathrm{O}_{3}$ data and meteorological reanalysis data, we analyze the impact of EMEs on $\mathrm{O}_{3}$ during $\mathrm{O}_{3}$ season of April-October in 2006-2017 over the PRD. Statistical analysis indicates significant but spatially heterogeneous sensitivities of $\mathrm{O}_{3}$ to EMEs. AS poses the largest impact on $\mathrm{O}_{3}$ concentration over the PRD, resulting in 58\% increase compared with normal days, while the increases by HW and TI are $28 \%$ and $14 \%$, respectively. $\mathrm{O}_{3}$ pollution events are largely initiated by $\mathrm{HW}$ and AS which favor formation and build-up of $\mathrm{O}_{3}$, while $\mathrm{O}_{3}$ pollution events are maintained mostly by persistent AS and TI. HW poses higher impacts on northern and eastern PRD, while AS impacts more on central and western PRD. The effect of AS on $\mathrm{O}_{3}$ concentration is similar as $10 \mathrm{~K}$ temperature increase during non-AS days, while the effect of $\mathrm{AS}$ and TI on $\mathrm{O}_{3}$ exceedance is comparable with $6 \mathrm{~K}$ temperature increase during non-EMEs condition. $\mathrm{O}_{3}$ concentrations under different synoptic patterns are largely associated with the occurrence of AS, and Siberian high and the approaching of a tropical cyclone are the dominant synoptic patterns for EMEs impact on $\mathrm{O}_{3}$ and largely determines the long-term increasing trend of $\mathrm{O}_{3}$ concentration over the PRD. This study highlights the importance of establishing a location-specific $\mathrm{O}_{3}$ control strategy targeting on normal conditions and $\mathrm{O}_{3}$ pollution events separately. This study also provides scientific support to use EMEs forecast as an indicator to implement contingency $\mathrm{O}_{3}$ control in advance so as to maximize peak $\mathrm{O}_{3}$ reduction over the PRD.
\end{abstract}

Keywords: Extreme meteorological events; $\mathrm{O}_{3}$; Synoptic patterns; Spatial heterogeneity; Pearl River Delta.

\section{INTRODUCTION}

Ozone $\left(\mathrm{O}_{3}\right)$, one of the most important air pollutants for its detrimental impact on human health, is formed through complex photochemical interactions in the presence of volatile organic compounds (VOCs), nitrogen oxides $\left(\mathrm{NO}_{\mathrm{x}}\right)$ and sunlight. Different from Europe and the United States where ground-level $\mathrm{O}_{3}$ pollution has alleviated extensively (Chang et al., 2017; Derwent et al., 2018; McGlynn et al., 2018), the observed $\mathrm{O}_{3}$ in South and East Asia, especially in China, has increased significantly since the 1980s (Zhang et al., 2016a).

To protect public health, China has formulated and implemented a series of stringent air pollution control measures since 2013, mainly targeting on $\mathrm{PM}_{2.5}, \mathrm{SO}_{2}$ and $\mathrm{NO}_{\mathrm{x}}$ (Du et al., 2017; Lin et al., 2018). In response, ambient concentration of $\mathrm{PM}_{2.5}$ has dropped by over $30 \%$ in the

\footnotetext{
* Corresponding author.

E-mail address: zibing@scut.edu.cn
}

recent five years (Fontes et al., 2017; Zhang et al., 2018b; $\mathrm{Ke}$ et al., 2019). $\mathrm{O}_{3}$, on the contrary, is still in an increasing trend (Li et al., 2017; Wang et al., 2017a; Wang et al., 2017b; Cheng et al., 2018). As one of the most populous and economically developed city clusters in China, Pearl River Delta (PRD) follows the same increasing trend on $\mathrm{O}_{3}$ concentration (Ou et al., 2015; Ou et al., 2016; Hou et al., 2018). Statistics show that $\mathrm{O}_{3}$ annual average increases from $25 \mathrm{ppb}$ to $30 \mathrm{ppb}$ and the $90^{\text {th }}$ percentile increases from $71 \mathrm{ppb}$ to $84 \mathrm{ppb}$ over the PRD during 2006-2017. $\mathrm{O}_{3}$ exceedance rate increases from $1.5 \%$ to $12.1 \%$ during the same period (Department of Ecology and Environment of Guangdong Province, http://www.gdep.gov.cn/hjjce/kqjc/).

Ambient $\mathrm{O}_{3}$ concentration is governed by both meteorological condition and emissions of its precursors, VOCs and $\mathrm{NO}_{\mathrm{x}}$. Emissions of precursors tend to be stable during a short period of time (hours to days), therefore $\mathrm{O}_{3}$ pollution events are mainly driven by undesirable meteorological conditions. Studies have shown that some local extreme meteorological events (EMEs), such as heat wave (HW), air stagnation (AS), and temperature inversion (TI), are favourable for $\mathrm{O}_{3}$ formation and accumulation, 
leading to $\mathrm{O}_{3}$ pollution episodes (Black et al., 2010; Hou and $\mathrm{Wu}, 2016)$. Concurrence of EMEs and $\mathrm{O}_{3}$ pollution events would pose greater impact on human health (Son et al., 2012; Meehl et al., 2018).

HW is characterized by high temperature lasting for a period of time, mostly over three days. It is well known that temperature is the largest short-term covariate of high $\mathrm{O}_{3}$ in most regions, directly influencing chemical kinetic rates and $\mathrm{O}_{3}$ formation mechanism ( $\mathrm{Im}$ et al., 2011). $\mathrm{O}_{3}$ increases with temperature with a slope $\left(m_{O 3-T}\right)$ of $2-$ $8 \mathrm{ppb} \mathrm{K}^{-1}$ in the United States (Steiner et al., 2010), with increasing sensitivity to temperature at higher $\mathrm{O}_{3}$ concentration (Porter et al., 2015). Studies worldwide show that with longer duration of high temperature, HW is more closely associated with $\mathrm{O}_{3}$ pollution events. For example, $\mathrm{O}_{3}$ concentration increases significantly due to persistent high temperature and drought during the European $\mathrm{HW}$ in 2003 (Solberg et al., 2008). HW can result in $12 \mathrm{ppb} \mathrm{O}_{3}$ enhancement compared to non-HW days in the Yangtze River Delta region of China ( $\mathrm{Pu}$ et al., 2017). HW can increase the probability of $\mathrm{O}_{3}$ severe pollution by seven times during summertime in the United States (Hou and $\mathrm{Wu}, 2016) . \mathrm{O}_{3}$ and $\mathrm{HW}$ concur on the same day in the same grid cell for more than $50 \%$ of the time during AprilSeptember 1999-2013 in the northeastern United States (Schnell and Prather, 2017).

AS is associated with low wind speed and lack of precipitation that are not conducive to deposition and removal of $\mathrm{O}_{3}$ (Banta et al., 1998). Previous studies show that $\mathrm{O}_{3}$ increases with each successive stagnation day in the United States (Sun et al., 2017), and more frequent AS under high pressures in the southeastern United States increases $\mathrm{O}_{3}$ over most of the eastern coastal states ( $\mathrm{Zhu}$ and Liang, 2013). AS is also significantly associated with background $\mathrm{O}_{3}$ in the Houston-Galveston-Brazoria area (Lei et al., 2018). Similarly, TI results in weaker vertical mixing, also contributing significantly to air pollution (Sun et al., 2017; Tong et al., 2018). In general, acceleration of $\mathrm{O}_{3}$ production and weakened horizontal advection and vertical diffusion contribute to $\mathrm{O}_{3}$ concentration increase (Wu et al., 2017). In brief, long-lasting $\mathrm{HW}$ promotes $\mathrm{O}_{3}$ formation, and $\mathrm{AS}$ and TI helps $\mathrm{O}_{3}$ pollution build-up (Banta et al., 1998; Fiore et al., 2015; Garrido-Perez et al., 2018).

Local meteorological conditions are essentially governed by the meso-scale synoptic systems, and their influence on air pollutants tend to differ by different circulation patterns. For instance, $\mathrm{O}_{3}$ pollution in the United States is often associated with cyclones and slow-moving anticyclones that accumulate pollutants and heat owing to the overlying meteorological conditions, e.g., high temperature, abundant solar insolation, and stable atmospheric conditions (Leibensperger et al., 2008; Jacob and Winner, 2009). Similar influence from anticyclones and tropical cyclones has also been found in China and the Malaysia peninsula (Zhang et al., 2013; Oozeer, 2016; Zhang et al., 2016c; Lam et al., 2018). In addition, by changing local prevailing wind, meso-scale circulation patterns also pose significant influence on the relative contribution between local production and non-local transport of $\mathrm{O}_{3}$ (Ngan and Byun, 2011; Shu et al., 2017). Current studies are mostly concentrated on the relationship between synoptic patterns and surface $\mathrm{O}_{3}$ concentration, but few of them have analyzed the interaction between meso-scale synoptic patterns, local EMEs, and $\mathrm{O}_{3}$ concentrations and exceedances.

In this study, we use surface observations of $\mathrm{O}_{3}$ concentration and reanalysis data of meteorological parameters in the extended summer (April-October) from 2006 to 2017 to investigate the impact of EMEs on $\mathrm{O}_{3}$ and their spatiotemporal characteristics over the PRD. Such impacts are examined in more detail under different mesoscale circulation patterns to reveal the underlying synoptic drivers of $\mathrm{O}_{3}$ pollution events. A good understanding on the meteorological influences on the surface concentration and pollution event occurrence of $\mathrm{O}_{3}$ is crucial to better formulate $\mathrm{O}_{3}$ control strategies to protect human health in the PRD.

\section{METHODS}

\section{Monitoring Data}

The PRD region covers nine cities in Guangdong Province and two special administrative regions of China, Hong Kong and Macao (Fig. S1). A PRD regional air quality monitoring network was jointly established by Guangdong and Hong Kong in 2005. Hourly $\mathrm{O}_{3}$ data during 20062017 at fourteen air monitoring stations in this network are used in this study, including ten in Guangdong and four in Hong Kong. The fourteen stations include Tsuen Wan (TW), Tung Chung (TC), Yuen Long (YL), Tap Mun (TM), Luhu (LH), Tianhu (TH), Liyuan (LY), Tangjia (TJ), Huijingcheng (HJC), Donghu (DH), Chengzhong (CZ), Xiapu (XP), Jinguowan (JGW), and Zimaling (ZML), as shown in Fig. S1.

Every day, the highest maximum daily 8-hour average (MDA8) is calculated from the reported hourly average $\mathrm{O}_{3}$ data. Further calculation on the average, $90^{\text {th }}$ percentile, and exceedance rate of $\mathrm{O}_{3}$ is based on the daily MDA8. As most of $\mathrm{O}_{3}$ pollution events occur in summer and fall over the PRD, our analysis only considers days during the extended summer season (April 1-October 31), and this period is defined as $\mathrm{O}_{3}$ season in the PRD. We follow but slightly modify the definition of $\mathrm{O}_{3}$ extremes $\left(\mathrm{O}_{3} \mathrm{X}\right)$ by Schnell and Prather (2017) as the MDA8 $\mathrm{O}_{3}$ greater than its $90^{\text {th }}$ percentile over April-October in each year. There are 2568 days in our study period, therefore $260 \mathrm{O}_{3} \mathrm{X}(10 \%)$ are identified at each site, and they are roughly evenly distributed across the twelve years.

\section{EMES}

Three EME parameters, HW, AS and TI, are used to examine their impact on $\mathrm{O}_{3}$. Although $\mathrm{HW}$ has become a popular extreme weather phenomenon along with rising global surface temperature (IPCC, 2014), there is no universal definition of HW (Theoharatos et al., 2010). In this study, HW is defined as daily maximum temperature at a given location exceeding $305 \mathrm{~K}$ for three consecutive days or longer. This definition is based on slight modification of the one used by Robinson (2001), Zhai and Pan (2003), 
World Meteorological Organization (2015), and Wang et al. (2016b) taking into consideration temperature distribution in the PRD. The definition of AS by National Climatic Data Center (NCDC) is used in this study, i.e., a day is considered as AS day when the following three conditions are fulfilled simultaneously: daily mean $10 \mathrm{~m}$ wind speed less than $3.2 \mathrm{~m} \mathrm{~s}^{-1}$, daily mean $500 \mathrm{mb}$ wind speed less than $13.0 \mathrm{~m} \mathrm{~s}^{-1}$, and daily total precipitation less than 1.0 $\mathrm{mm}$ (Horton et al., 2014). Definition of TI by Hou and $\mathrm{Wu}$ (2016) is used with slightly modification, i.e. a day with temperature at $2 \mathrm{pm}$ at a higher level below $800 \mathrm{hPa}$ is at least $0.1 \mathrm{~K}$ higher than the temperature at a lower level.

All the meteorological data for EMEs ( $2 \mathrm{~m}$ temperature for $\mathrm{HW} ; 10 \mathrm{~m}$ wind speed, $500 \mathrm{mb}$ wind speed, total precipitation for AS; temperature of $800,825,850,875,900$, $925,950,975$ and $1000 \mathrm{hPa}$ for $\mathrm{TI}$ ) are obtained from the European Centre for Medium Weather Forecast (ECMWF; http://apps.ecmwf.int/datasets/data/interim-fulldaily/levtyp $\mathrm{e}=\mathrm{sfc} /$ ) ERA-Interim re-analysis with spatial resolution of $0.125^{\circ} \times 0.125^{\circ}$ and temporal resolution of 3 hours for $2 \mathrm{~m}$ temperature, $10 \mathrm{~m}$ wind speed and total precipitation and 6 hours for $500 \mathrm{mb}$ wind speed and temperature at 800 $1000 \mathrm{hPa})$. We have undertaken a comparison of meteorological datasets between observed and reanalyzed temperature and wind speed at Hong Kong Observatory (HKO), Guangzhou Baiyun International Airport (GZ-BY) and Qingyuan (QY) stations (Fig. S2). Temperature at HKO, wind speed at GZ-BY and temperature and wind speed at QY show good matches between observation and reanalysis. Reanalyzed wind speed at HKO is greater than observation due much to the coarse land-use in urban Hong Kong, while reanalyzed temperature at GZ-BY is lower than observation due to the significantly lower heat capacity of cement and asphalt ground in the airport that could reflect much heat to back the atmosphere.

\section{Ozone Spatial Interpolation}

Inverse Distance Weighting (IDW) interpolation method is adopted for $\mathrm{O}_{3}$ spatial interpolation in this study. IDW interpolation method is a type of deterministic method for multivariate interpolation with a known scattered set of points. The assigned values to unknown points are calculated with a weighted average of the values available at the known points. IDW interpolation method is used for analysing the spatial distribution characteristics of $\mathrm{O}_{3}$ concentrations and frequencies of EMEs in this study. IDW interpolation is shown in Eq. (1):

$$
Z_{i}=\frac{\sum_{j=1}^{n} Z_{j} / d_{j}^{m}}{\sum_{j=1}^{n} 1 / d_{j}^{m}}
$$

where $Z_{i}$ is the estimated value of interpolation point $i, Z_{j}$ is the value of monitoring station $j, N$ means the amount of monitoring stations, $d_{i}$ means the distance from each monitoring station to the interpolation point $i, m$ means the power and is also a control parameter, generally assumed as two as used by Ozelkan et al. (2015), it is also the default value in ArcGIS10.2.

It should be noted that IDW interpolation do not represent the actual $\mathrm{O}_{3}$ concentration. It is mainly used to describe the general pattern of spatial distribution of $\mathrm{O}_{3}$ across all monitoring sites of the PRD. IDW interpolation was also used in the various studies for description of $\mathrm{O}_{3}$ spatial distribution, e.g., Hou and $\mathrm{Wu}$ (2016) and Liao et al. (2018).

\section{Classification of Synoptic-scale Circulation Patterns}

Classification of synoptic-scale circulation patterns is widely conducted in previous studies by either subjective or objective method (El-Kadi and Smithson, 1992). Synoptic weather patterns provide an explicit understanding of potential dynamic mechanisms that control ambient pollution. In this study, we develop a semi-objective technique by combining the methods developed by Heywood et al. (1953), Kirchhofer (1973), Zhang et al. (2013), and Zhang et al. (2016b), as explained in brief below.

The semi-objective classification of circulation patterns consists of the following steps. First, as approaching of a tropical cyclone is one of the most important weather patterns leading to $\mathrm{O}_{3}$ pollution in the PRD (Huang et al., 2006), we firstly pick out all days with an identifiable tropical cyclone in the study domain, and separate them into two categories according to the distance of the storm center to the PRD: Cyclone I between PRD and Taiwan with a distance less than $600 \mathrm{~km}$, and Cyclone II in the East China Sea with a distance between $600 \mathrm{~km}$ and $1000 \mathrm{~km}$ (Heywood et al., 1953; Zhang et al., 2013). Afterwards, Kirchhofer's objective weather classification method is used to classify other synoptic-scale circulation patterns. The gridded MSLP data is normalized using Eq. (2):

$$
Z_{i}=\frac{\left(X_{i}-\bar{X}\right)}{S}
$$

where $Z_{i}$ is the normalized value for grid $i, X_{i}$ is data value for grid $i, \bar{X}$ is the averaged value for the study domain, and $S$ is the standard deviation. This process is aimed to eliminate seasonal variations in horizontal pressure gradients, making the values of different seasons comparable (Barry and Kiladis, 1981; El-Kadi and Smithson, 1992).

Kirchhofer score $(S)$ is then computed for each pair of days by Eq. (3):

$$
S_{k b}=\sum_{i=1}^{N}\left(Z_{k i}-Z_{b i}\right)^{2}
$$

where $Z_{k i}$ and $Z_{b i}$ are the normalized values for grid $i$ on day $k, b$, respectively. $N$ is equal to the number of points in the study domain. The Kirchhofer scores, $S_{C}, S_{R}$, and $S_{T}$, are calculated for each column $\left(N_{C}=\right.$ No. of rows, 61), row $\left(N_{R}=\right.$ No. of columns, 81$)$, and the entire domain $\left(N_{T}=\right.$ No. of columns $\times$ rows, 4941), respectively, by Eq. (3). This process is intended to ensure that the weather patterns across the region are similar. If $S_{C}, S_{R}$, and $S_{T}$ meet 
threshold requirements $\left(S_{T}\right.$ of $1.0 N_{T}, S_{C}$ of $1.8 N_{C}$, and $S_{R}$ of $1.8 N_{R}$ ) (Moritz, 1979), the circulation patterns on the pair of days are considered similar. The day with a circulation pattern that is similar to those on the largest number of days is considered as a representative day of one pattern and is removed from analysis along with all days similar to it, and this process is repeated to identify subsequent six representative days (after removing the first seven representative days with all days categorized to them, there are no more notable representative days). Finally, $S_{R}, S_{C}$, and $S_{T}$ are calculated again for each of the total population of days (except days in the two tropical cyclone categories) with those seven representative days. All days are then classified into one of the patterns if Kirchhofer score is lowest with the representative day of the pattern. Based on thirty nine years (1979-2017) of gridded mean sea level pressure $(\mathrm{MSLP})$ data with $0.5^{\circ} \times 0.5^{\circ}$ horizontal resolution over the domain of $100^{\circ} \mathrm{E}-140^{\circ} \mathrm{E}$ in longitude, $10^{\circ} \mathrm{N}-40^{\circ} \mathrm{N}$ in latitude from the ECMWF ERA-Interim re-analysis (Fig. S3, with $61 \times 81=4941$ grids), nine synoptic-scale circulation patterns are classified.

\section{RESULTS AND DISCUSSION}

\section{Spatial Concurrences of EMEs and MDA8 Ozone}

Although with a rough size of $200 \mathrm{~km} \times 200 \mathrm{~km}$ only, the PRD exhibits significant spatial heterogeneity of EMEs and MDA8 $\mathrm{O}_{3}$, as shown in Fig. 1. The frequency of $\mathrm{HW}$, AS and TI days in the PRD is $19 \%, 17 \%$ and $9 \%$ in the extended summer of 2006-2017, respectively. HW and TI occur more frequently in central and western PRD while AS mostly in northeastern PRD. Mean MDA8 $\mathrm{O}_{3}$ concentration $\left(\mathrm{O}_{3 \mathrm{M}}\right)$ and mean $90^{\text {th }}$ percentile of MDA8 $\mathrm{O}_{3}$ concentration $\left(\mathrm{O}_{3-90}\right)$ range from 50 to $135 \mu \mathrm{g} \mathrm{m}^{-3}$ and 104 to $214 \mu \mathrm{g} \mathrm{m}^{-3}$ at different stations, with a region-wide increase rate of 2 and $3 \mu \mathrm{g} \mathrm{m}^{-3} \mathrm{yr}^{-1}$, respectively. $\mathrm{O}_{3 \mathrm{M}}$ and $\mathrm{O}_{3-90}$ show the highest level at the TH station in the northern PRD due mainly to its geographical location that is downwind of the central PRD, where most of the local pollutants are emitted, during $\mathrm{O}_{3}$ season in summer and fall by the southwesterly prevailing wind. Pollutants emitted from the central PRD react to form $\mathrm{O}_{3}$ along with transport to the downwind $\mathrm{TH}$ areas. Different from $\mathrm{O}_{3 \mathrm{M}}$, higher $\mathrm{O}_{3-90}$ are also found over the western and central PRD, the area with higher occurrence of EMEs, in particular HW and TI. Similar spatial distribution between $\left(\mathrm{O}_{3-90}-\mathrm{O}_{3 \mathrm{M}}\right)$ and EMEs might imply potential relationships between $\mathrm{O}_{3} \mathrm{X}$ and EMEs in this region.

We further examine the relationship by analyzing the concurrence of $\mathrm{O}_{3} \mathrm{X}$ and EMEs across the PRD region expressed as four combinations $\left(\mathrm{O}_{3} \mathrm{X}+\mathrm{HW}, \mathrm{O}_{3} \mathrm{X}+\mathrm{AS}\right.$, $\mathrm{O}_{3} \mathrm{X}+\mathrm{TI}$, and $\mathrm{O}_{3} \mathrm{X}+\mathrm{HW}+\mathrm{AS}$ ). As illustrated in Fig. 2, although the spatial distributions of $\left(\mathrm{O}_{3-90}-\mathrm{O}_{3 \mathrm{M}}\right)$ and HW/TI are more similar, $\mathrm{O}_{3} \mathrm{X}+\mathrm{AS}$ shows overall the highest concurrence rate of $43 \%$, which is defined as the occurrence frequency of EMEs during $\mathrm{O}_{3} \mathrm{X}$, followed by $\mathrm{O}_{3} \mathrm{X}+\mathrm{HW}$ of $33 \%, \mathrm{O}_{3} \mathrm{X}+\mathrm{HW}+\mathrm{AS}$ of $13 \%$, and $\mathrm{O}_{3} \mathrm{X}+\mathrm{TI}$ of $10 \%$. The frequencies of $\mathrm{HW}$ and AS during $\mathrm{O}_{3} \mathrm{X}$ events increase significantly in comparison with the all-time average of
$19 \%$ and $17 \%$, respectively, while that of TI does not change much from the all-time average of $9 \%$. This indicates that TI functions little in initiating $\mathrm{O}_{3} \mathrm{X}$ events. In addition, concurrence of $\mathrm{O}_{3} \mathrm{X}$ and $\mathrm{AS}$ is more prominent in central and western PRD, while that of $\mathrm{O}_{3} \mathrm{X}$ and $\mathrm{HW}$ is more prominent in northern and eastern PRD. Such spatially different concurrence characteristics may imply different roles of $\mathrm{HW}$ and $\mathrm{AS}$ in driving $\mathrm{O}_{3} \mathrm{X}$ events in different parts of the PRD, as also evidenced by the significantly lower frequency of $\mathrm{O}_{3} \mathrm{X}+\mathrm{HW}+\mathrm{AS}$. $\mathrm{O}_{3} \mathrm{X}+$ $\mathrm{HW}+\mathrm{AS}$ shares similar spatial distribution with $\mathrm{O}_{3} \mathrm{X}+$ $\mathrm{HW}$, suggesting that $\mathrm{HW}$ is the driving factor for $\mathrm{O}_{3} \mathrm{X}$ events in northern and eastern PRD.

\section{Impact of EMEs on MDA8 Ozone}

In this section, we examine the magnitude of EMEs influence on $\mathrm{O}_{3}$ by comparing the average concentration and exceedance rate of $\mathrm{O}_{3}$ on EME days with those on non-EME days. Figs. 3(a), 3(b) and 3(c) show percentage changes of mean $\mathrm{O}_{3}$ concentration on $\mathrm{HW}$, AS and TI days compared to those on non-EME days. As expected, $\mathrm{O}_{3}$ concentration on EME days are substantially higher than those on non-EME days over most of the PRD region.

AS results in the greatest enhancement on $\mathrm{O}_{3}$ level by $58 \%\left(51 \mu \mathrm{g} \mathrm{m}^{-3}\right)$ compared with those on non-AS days, and the highest sensitivities are found over central and western PRD. HW enhances $\mathrm{O}_{3}$ level by $28 \%\left(27 \mu \mathrm{g} \mathrm{m}^{-3}\right)$, with higher sensitivities in the northern and eastern PRD. Such spatial distributions coincide well with those of concurrent frequencies between $\mathrm{O}_{3} \mathrm{X}$ and EMEs (Fig. 2), but are different from the occurrence frequencies of EMEs themselves (Fig. 1). This indicates spatial discrepancy between EMEs occurrences and their impacts on $\mathrm{O}_{3}$, and such a spatial discrepancy is largely caused by the spatial heterogeneity in emissions of $\mathrm{O}_{3}$ precursors. In comparison, the effect of TI on $\mathrm{O}_{3}$ level is relatively weaker (enhanced by $14 \%, 10 \mu \mathrm{g} \mathrm{m}^{-3}$ ) throughout the PRD region. TI increases $\mathrm{O}_{3}$ in the southern PRD but decreases it in the north/northwestern PRD. It is noted that the $\mathrm{O}_{3}$ concentration hotspot around $\mathrm{TH}$ station does not have a notable relationship with EMEs, suggesting $\mathrm{O}_{3}$ at $\mathrm{TH}$ is overall mainly transported rather than formed locally.

Apart from $\mathrm{O}_{3}$ concentration, we further examine the impact of EMEs on $\mathrm{O}_{3}$ exceedance rate, as illustrated in Figs. 3(e)-3(g). AS is again the EME that poses the largest impact on $\mathrm{O}_{3}$ exceedance. $\mathrm{O}_{3}$ exceedance rate under $\mathrm{AS}$ is 4.0 times higher than non-AS, and is even higher in the central and western PRD. HW increases $\mathrm{O}_{3}$ exceedance rate by 2.5 times, and is more pronounced in the northern and eastern PRD. TI still makes the least difference to $\mathrm{O}_{3}$ exceedance rate, and even slightly reduces $\mathrm{O}_{3}$ exceedance rate over some areas in the northern/northeastern PRD. All of the above results reveal that the EMEs made a considerable contribution to the deterioration of $\mathrm{O}_{3}$. It is noted that $\mathrm{HW}$ poses a relatively larger impact on $\mathrm{O}_{3}$ exceedance at $\mathrm{TH}$ than on mean $\mathrm{O}_{3}$ concentration. This suggests that local $\mathrm{O}_{3}$ production becomes prominent during $\mathrm{O}_{3} \mathrm{X}$ events at TH.

Figs. 3(d) and 3(h) show the enhancement of $\mathrm{O}_{3}$ concentration and exceedance rate by the concurrence of 


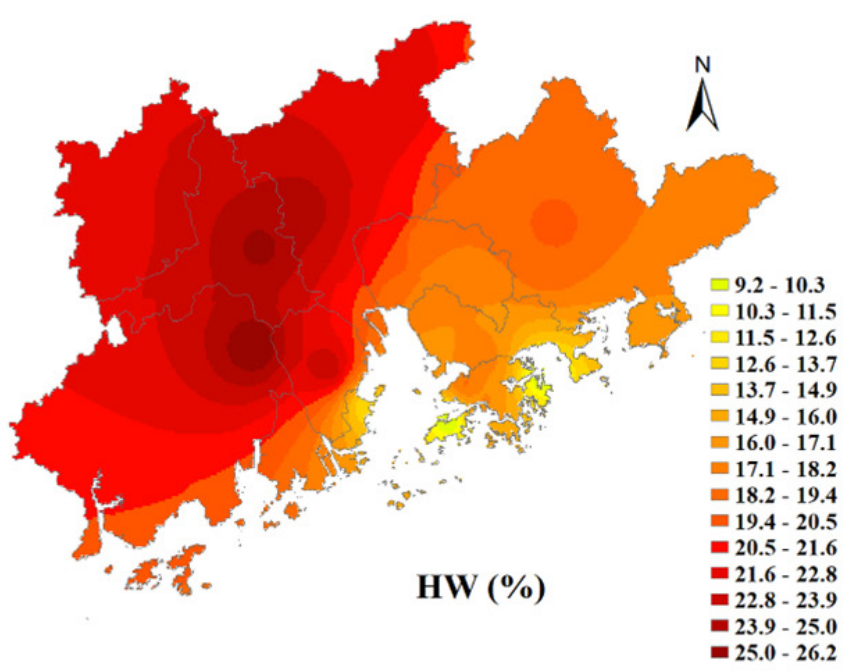

(a)

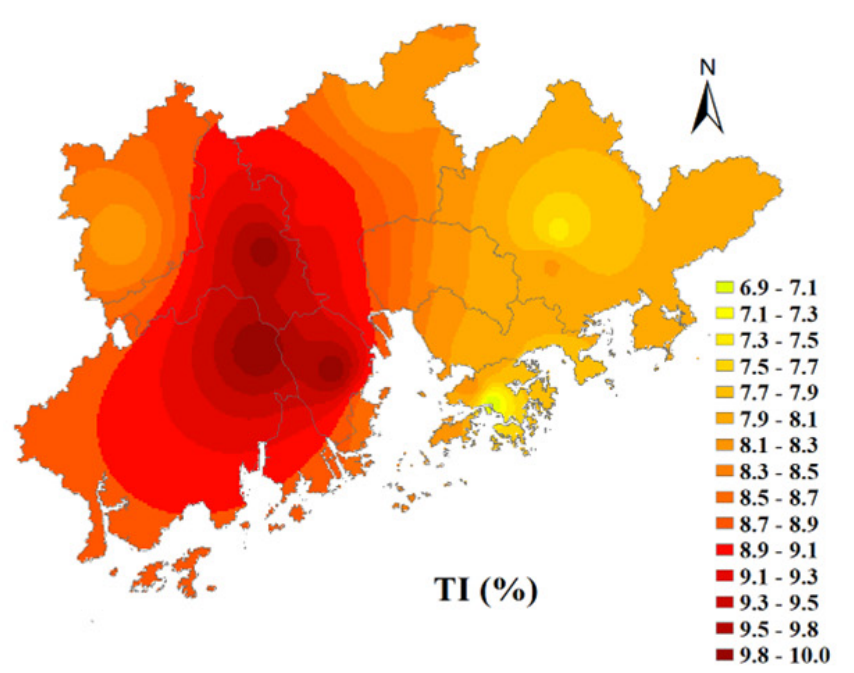

(c)

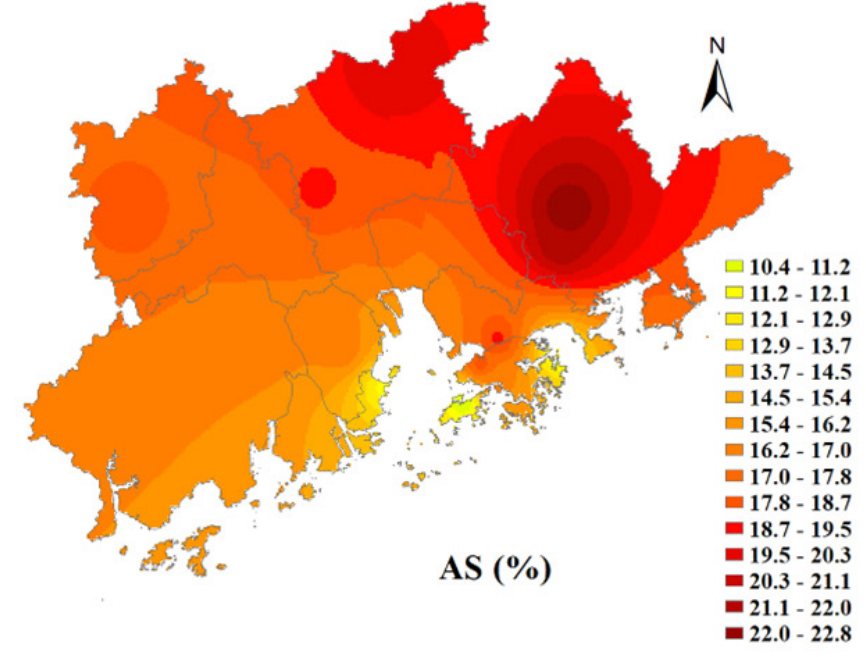

(b)

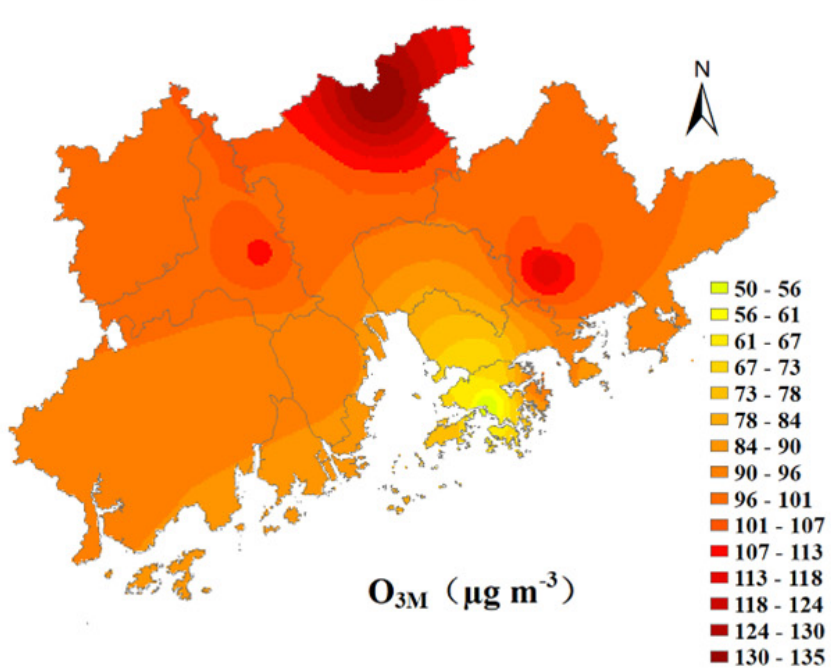

(d)

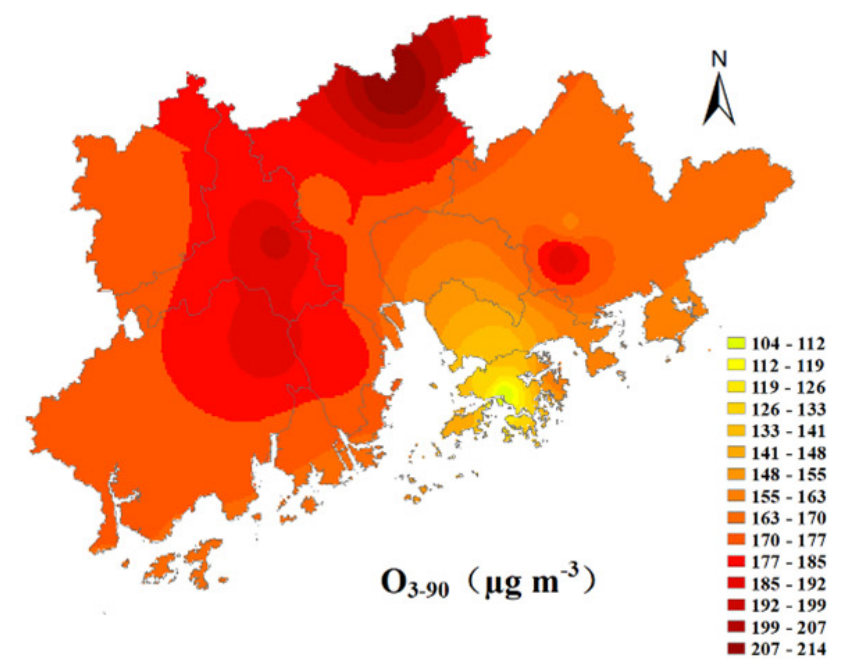

(e)

Fig. 1. Spatial distribution of occurrence frequencies of (a) HW, (b) AS, (c) TI, and spatial distribution of (d) mean MDA8 $\mathrm{O}_{3}$ concentration $\left(\mathrm{O}_{3 \mathrm{M}}\right)$ and (e) mean $90^{\text {th }}$ percentile of MDA8 $\mathrm{O}_{3}$ concentration $\left(\mathrm{O}_{3-90}\right)$ over the Pearl River Delta during April-October 2006-2017. 


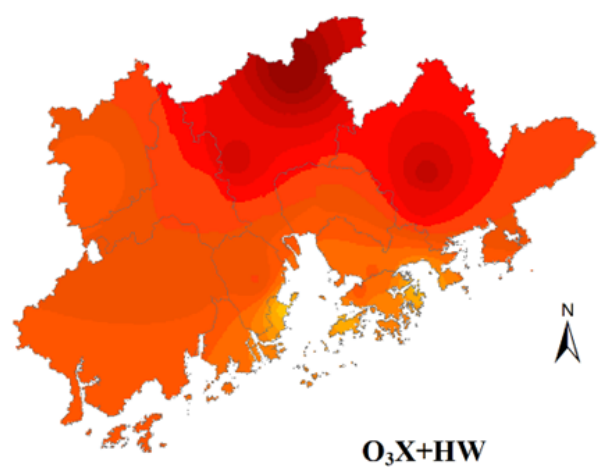

(a)

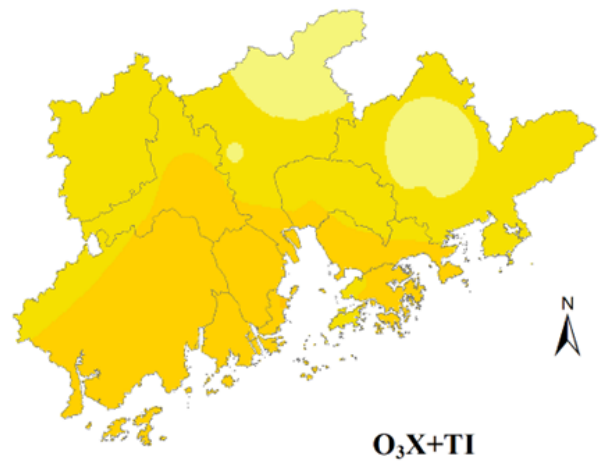

(c)

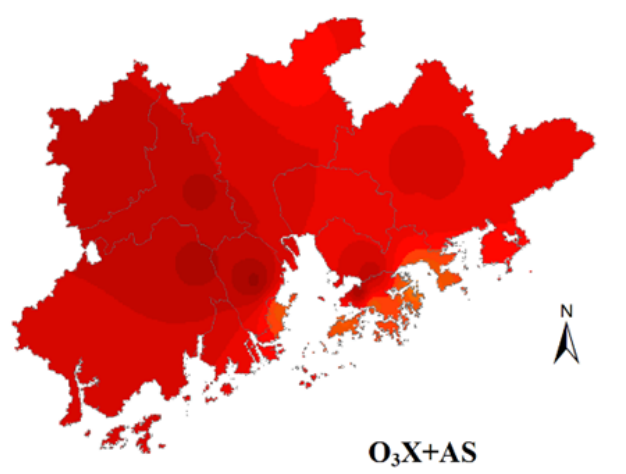

(b)

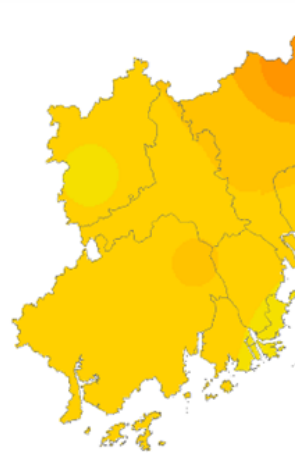

$\mathrm{O}_{3} \mathrm{X}+\mathrm{HW}+\mathrm{AS}$ $\square 5$ - 8

$\square$ 8 - 11

$\square 11$ - 14

$\square 14-17$

$\square 17-20$

$\square 20-23$

प 23 - 26

-26- 29

- 29 - 32

- 32 - 35

- 35 - 38

무 38 - 41

미 - 44

प 44 - 47

- 47 - 50

- 50 - 53

- $53-57$

(d)

Fig. 2. Concurrence frequency between $\mathrm{O}_{3} \mathrm{X}$ and (a) HW, (b) AS, (c) TI, and (d) HW $+\mathrm{AS}$.

$\mathrm{HW}$ and $\mathrm{AS} . \mathrm{O}_{3}$ concentration and exceedance rate are $38 \%$ and 2.6 times higher on HW + AS days than non-HW + AS days, respectively, which are lower than the effect of AS individual but higher than HW. This is different from what Zhang et al. (2018a) reported that concurrence of HW and AS greatly enhanced $\mathrm{O}_{3}$ concentration in the United States, in comparison with HW and AS individual, as both high temperature and low wind speed promote the production and accumulation of $\mathrm{O}_{3}$ concentration. In the PRD, as discussed previously, HW and AS function over different areas to increase $\mathrm{O}_{3}$, possibly by different mechanisms. The little overlap in functioning areas leads to the phenomenon that when one EME factor is driving an $\mathrm{O}_{3} \mathrm{X}$ event over an area, the addition of another EME factor does not assist much in further intensifying $\mathrm{O}_{3}$ pollution there.

To investigate the roles of EMEs in elevating $\mathrm{O}_{3}$ in different areas, we track changes in the frequencies of EMEs along with evolution of $\mathrm{O}_{3} \mathrm{X}$ events in the four quadrants of the PRD, as illustrated in Fig. 4. It is noticed that HW and AS frequencies start to increase 3 days before $\mathrm{O}_{3} \mathrm{X}$ events, making a favorable condition for $\mathrm{O}_{3}$ production and accumulation. After initiation of $\mathrm{O}_{3} \mathrm{X}$ events, AS frequency keeps increasing for multiple days in NW, SW and SE quadrants. HW frequency increases slightly in NW and NE quadrants but decreases in SW and SE quadrants. There is also a clear upward trend of TI frequency after the second day of $\mathrm{O}_{3} \mathrm{X}$ in NW, NE and SW quadrants. Hence, it may conclude that $\mathrm{O}_{3} \mathrm{X}$ events in the PRD are largely initiated by HW and AS which favor formation and build-up of $\mathrm{O}_{3}$, while $\mathrm{O}_{3} \mathrm{X}$ events are maintained mostly by persistent AS and TI, especially in NW and SW quadrants. HW helps in maintaining $\mathrm{O}_{3} \mathrm{X}$ events in $\mathrm{NW}$ and $\mathrm{NE}$ quadrants but with lower degree and shorter period. NE is the only quadrant with $\mathrm{O}_{3} \mathrm{X}$ event maintained mainly by $\mathrm{HW}$, and is associated with decreasing $\mathrm{O}_{3}$ concentration along with time. This further highlights that AS is the most important EME factor that extends $\mathrm{O}_{3} \mathrm{X}$ events over the PRD.

\section{Impact of EMEs on MDA8 Ozone at Different Temperature Ranges}

The impacts of EMEs on $\mathrm{O}_{3}$ are further examined by its dependence on surface temperature. Fig. 5 shows a comparison between $\mathrm{O}_{3}$ concentration during EMEs and non-EMEs in each 2 degree interval between $284-312 \mathrm{~K}$ in the entire and four quadrants of the PRD. $\mathrm{O}_{3}$ concentrations during non-EMEs increases gradually with temperature, and the increase becomes more significantly when temperature rises over $306 \mathrm{~K}$. Relationships between $\mathrm{O}_{3}$ concentration and temperature for different EMEs are notably different. The red bars for HW only appear at the interval of 304$306 \mathrm{~K}$ and above, according to the definition of $\mathrm{HW}$ adopted in this study. Region-wide, $\mathrm{HW}$ increases $\mathrm{O}_{3}$ concentration slightly in comparison with non-HW days, suggesting that $\mathrm{O}_{3}$ concentration does not change much along with extension of high temperature days. This agrees well with the findings from (Sun et al., 2017) in the United States. However, NE quadrant presents a different picture. $\mathrm{O}_{3}$ concentration over NE quadrant even slightly decreases 


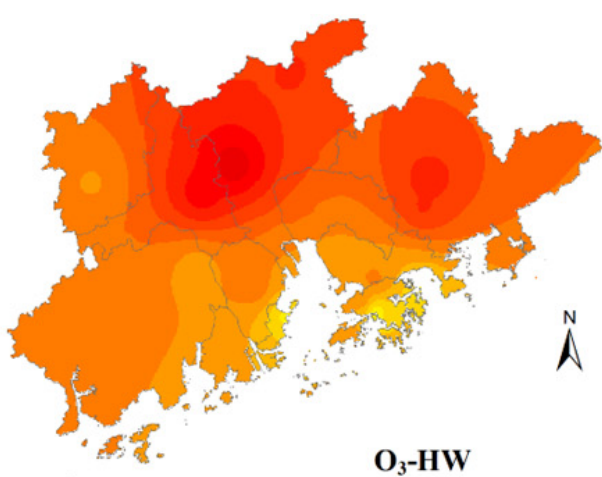

(a)

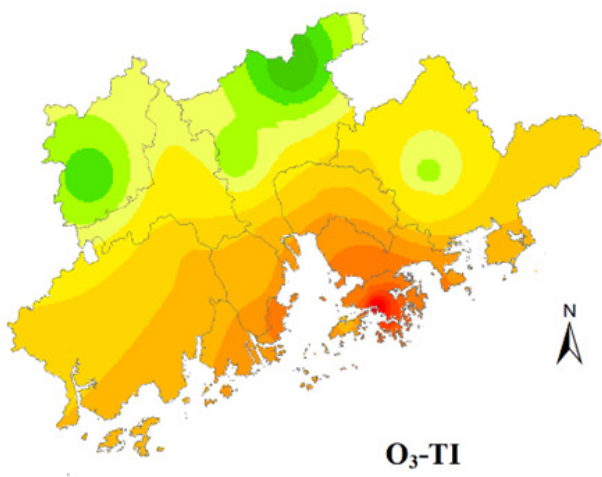

(c)

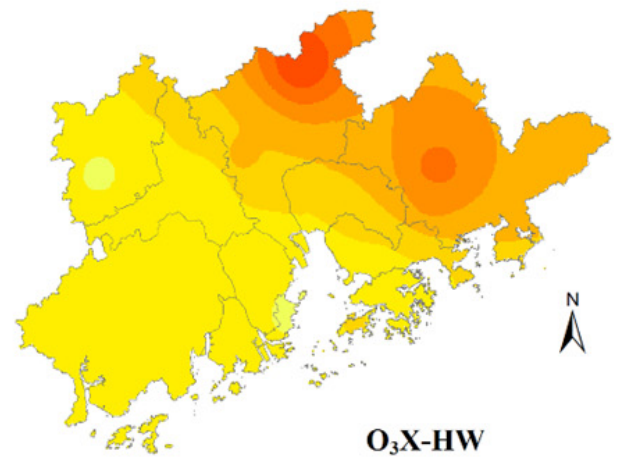

(e)

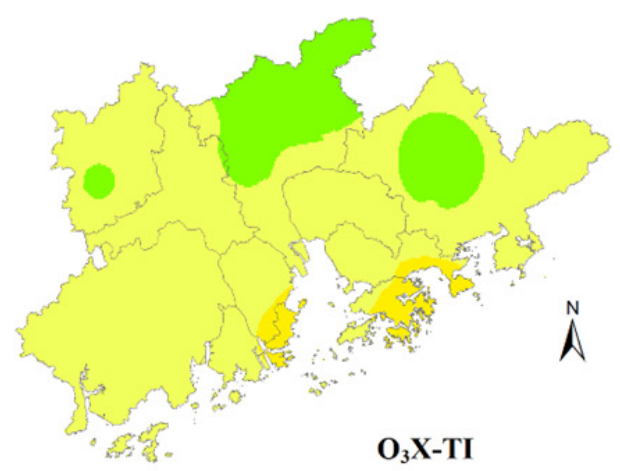

(g)

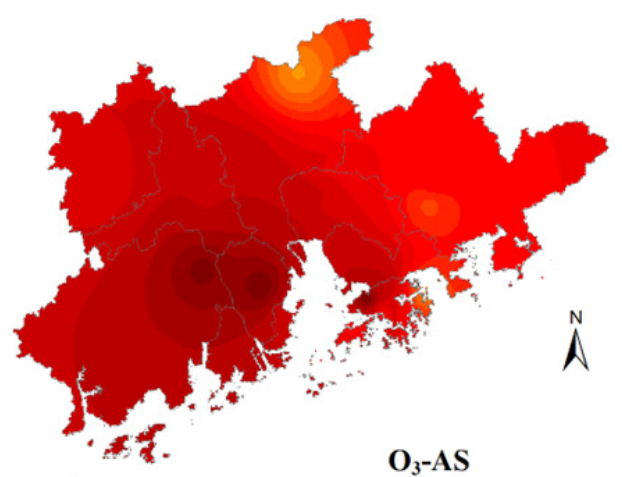

(b)

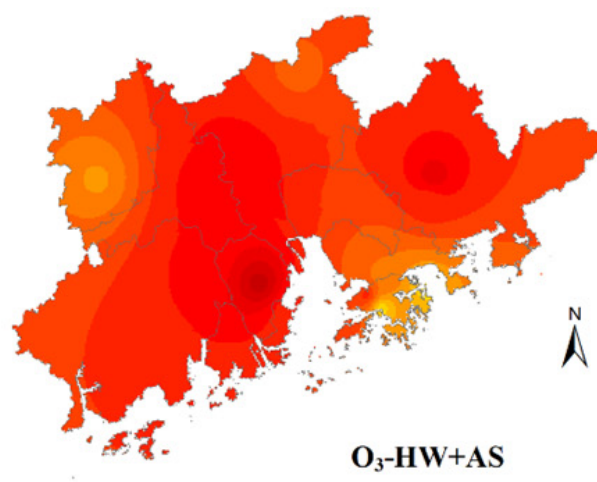

(d)

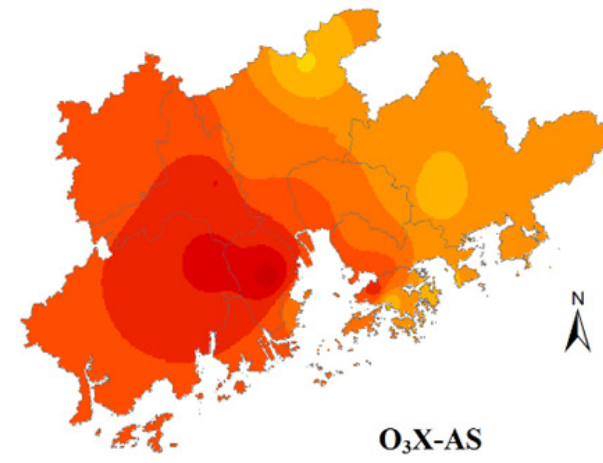

(f)

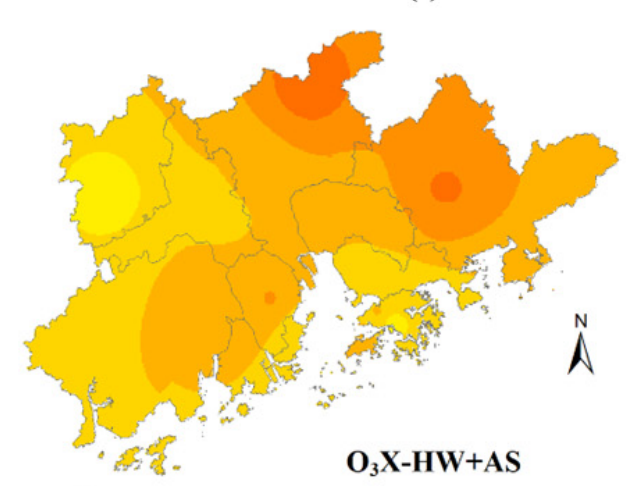

(h)

Fig. 3. Percentage changes (\%) in $\mathrm{MDA}_{8} \mathrm{O}_{3}$ concentration during (a) $\mathrm{HW}$, (b) AS, (c) TI, and (d) $\mathrm{HW}+\mathrm{AS}$ with respect to non-EMEs conditions, and changes in $\mathrm{O}_{3}$ exceedance rate during (e) $\mathrm{HW}$, (f) AS, (g) TI, and (h) $\mathrm{HW}+\mathrm{AS}$ with respect to non-EMEs conditions. 

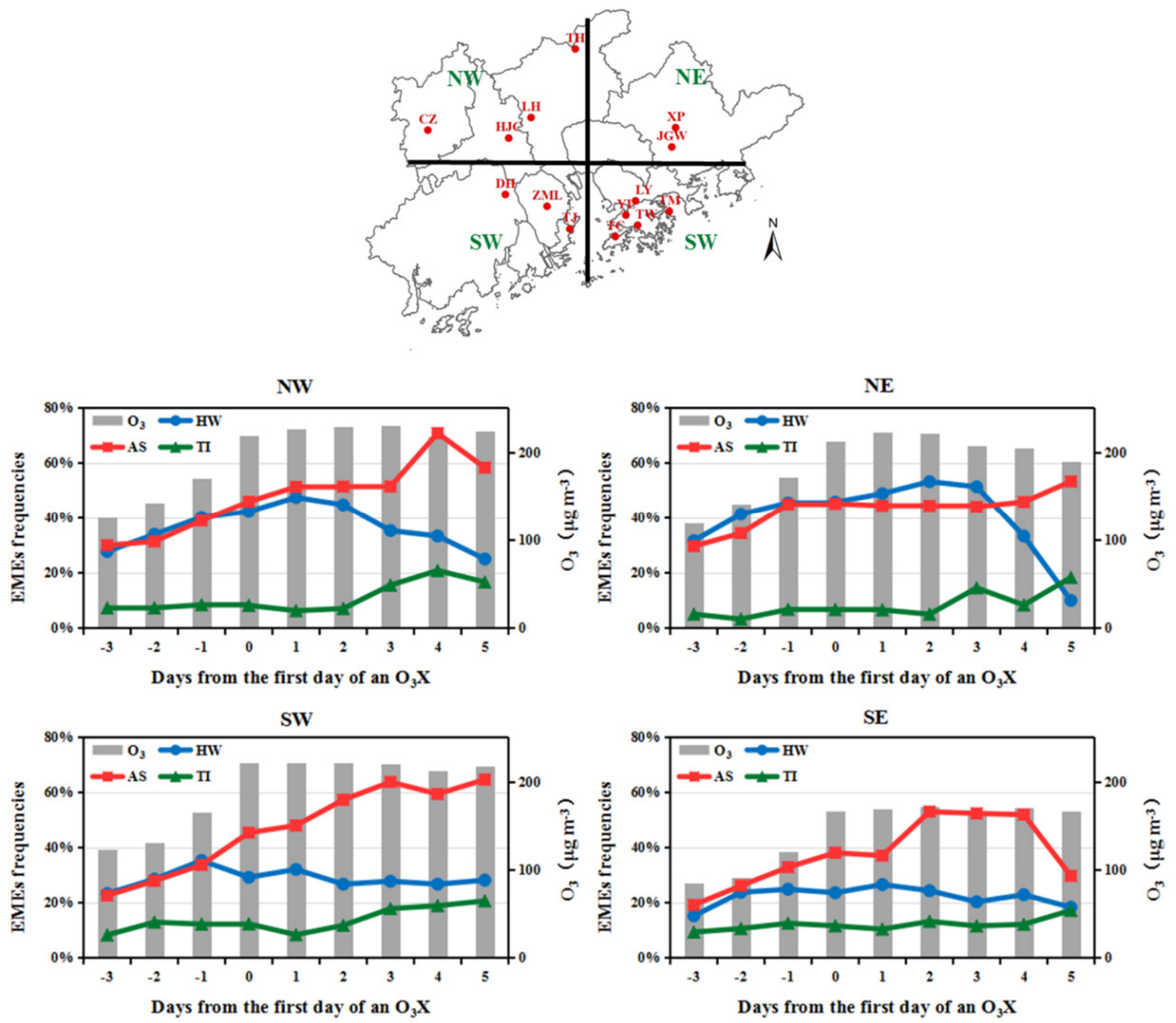

Fig. 4. Changes in $\mathrm{O}_{3}$ concentration and occurrence frequencies of EMEs along with evolution of $\mathrm{O}_{3}$ pollution events in the four quadrants of the Pearl River Delta.

when the temperature rises above $304 \mathrm{~K}$ but without $\mathrm{HW}$, and it increases significantly with HW. This suggests that $\mathrm{O}_{3}$ level in $\mathrm{NE}$ quadrant needs longer duration (over three days) of high temperature to build up, indicating lower $\mathrm{O}_{3}$ formation rate in comparison with other quadrants. This also confirms previous conclusion that $\mathrm{NE}$ is the only quadrant with $\mathrm{O}_{3} \mathrm{X}$ event maintained mainly by HW.

During non-AS days, $\mathrm{O}_{3}$ concentration generally levels off until temperature rises over $306 \mathrm{~K}$. In comparison, $\mathrm{O}_{3}$ concentration during AS days increases significantly when temperature rises over $296 \mathrm{~K}$. This highlights that the effect of $\mathrm{AS}$ on $\mathrm{O}_{3}$ concentration is similar as that of $10 \mathrm{~K}$ temperature increase. AS poses higher impact on $\mathrm{O}_{3}$ than HW and TI, especially when temperature ranges between 296-308 K. Spatially, when temperature is below 294 K, AS only occurs in the NW quadrant. When temperature rises above $296 \mathrm{~K}$, AS impact on $\mathrm{O}_{3}$ concentration is rapidly increasing, especially in the SW quadrant. In contrast, TI increases $\mathrm{O}_{3}$ concentration when temperature ranges between 296-306 K, and decreases $\mathrm{O}_{3}$ concentration when temperature is either higher or lower. The magnitudes of increase in different temperature intervals are similar. TI increases $\mathrm{O}_{3}$ concentration more significantly in $\mathrm{SW}$ and SE quadrants.

We further examine the temperature dependence of EMEs impact on $\mathrm{O}_{3}$ exceedance, as shown in Fig. S4. During non-EMEs, $\mathrm{O}_{3}$ exceedance occurs when temperature rises over $296 \mathrm{~K}$, and increases slightly until $308 \mathrm{~K}$ with a drastic increase. HW contributes to $\mathrm{O}_{3}$ exceedance in NW and NE quadrants when temperature is above $306 \mathrm{~K}$, and to that in SW and SE quadrants when temperature is above $308 \mathrm{~K}$. It is interesting to note that when temperature is above $308 \mathrm{~K}$, all exceedances occur with $\mathrm{HW}$, which highlights that extremely high temperature with short duration (less than three days) is not favorable for $\mathrm{O}_{3}$ exceedance. Steiner et al. (2010) found the same phenomenon 

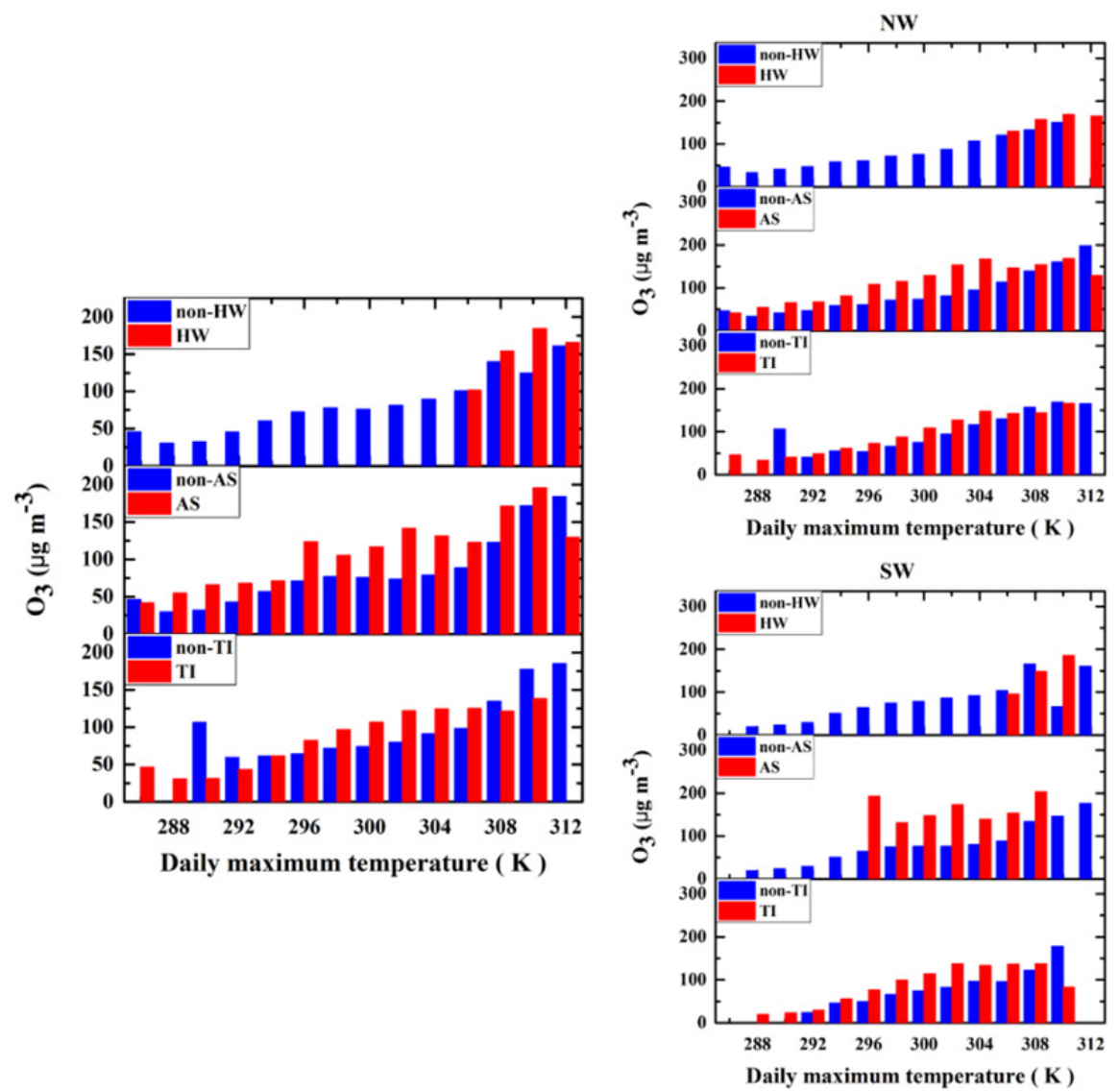

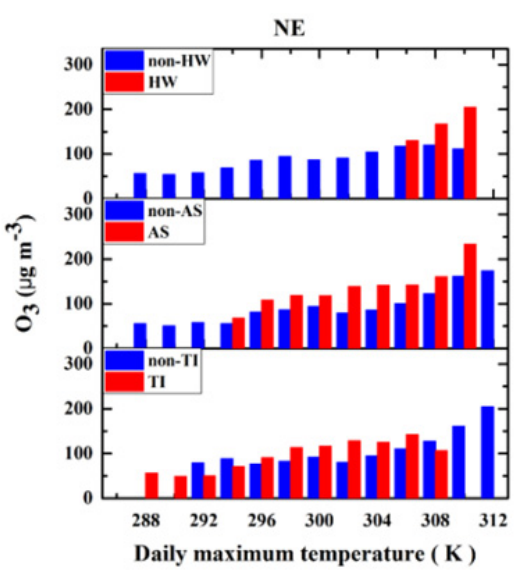

SE

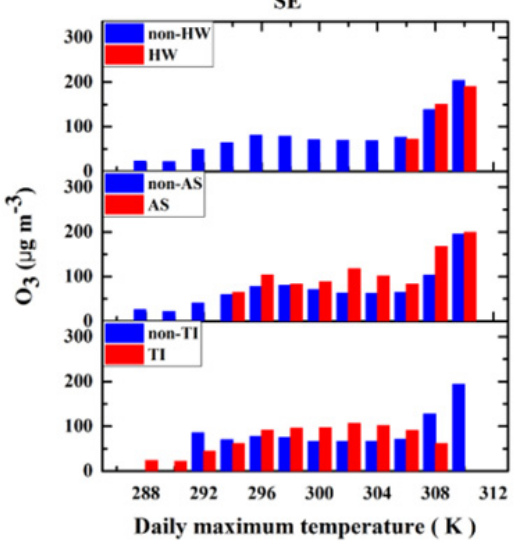

Fig. 5. Comparison of $\mathrm{O}_{3}$ concentration between EMEs and non-EMEs in each 2 degree interval between $284-312 \mathrm{~K}$ in the entire and four quadrants of the Pearl River Delta.

in the United States and proposed that it is due to decrease in peroxyacyl nitrates (PAN) lifetime leading to a decrease in the net PAN sink for $\mathrm{NO}_{\mathrm{x}}$. When temperature is above $310 \mathrm{~K}$, there is no $\mathrm{O}_{3}$ exceedance, no matter whether $\mathrm{HW}$ occurs or not. In comparison with HW, AS and TI lead to significant increase of $\mathrm{O}_{3}$ exceedance at $302 \mathrm{~K}, 6 \mathrm{~K}$ lower than non-EMEs condition. AS poses higher impacts on SW and SE quadrants, while the impact of TI is relatively spatially consistent.

\section{Impact of EMEs on MDA8 Ozone under Different Synoptic Patterns}

Large-scale synoptic patterns are the main drivers of EMEs, therefore we further examine the impacts of EMEs on $\mathrm{O}_{3}$ under different synoptic patterns. By applying the semi-objective classification method, nine predominant synoptic patterns are identified, as illustrated in Fig. 6. P1P3 are characterized by the dominance of the Siberian high, with differences in its location. As shown in Fig. S5, PRD experiences strong to moderate northeasterly winds under P1-P3, as surface pressure gradient over the PRD is high. Under P4 and P5, PRD is located at the western edge of a high pressure over Japan and of the western Pacific subtropical high, respectively. Under P6 and P7, PRD is largely controlled by a low pressure system centered over central China and the Gulf of Tonkin, respectively. Surface winds are weak and variable under P4-P7 for the low surface pressure gradient. Under P8 and P9, PRD is located in the outskirt of a tropical cyclone located in the South China Sea and East China Sea, respectively. The cyclonic circulation brings northerly winds over the PRD, and the wind speed is determined by the intensity of tropical cyclone and its distance to the PRD.

As shown in Table 1, P6, P7, P1, P4 and P2 are synoptic patterns occurring more frequently during the extended summer. $\mathrm{O}_{3}$ concentration and exceedance are relatively lower under P6 and P7 due mainly to the abundant rainfall in association with the low pressure system. Therefore, P1, $\mathrm{P} 2$ and $\mathrm{P} 4$ contribute the most significantly to $\mathrm{O}_{3}$ in the PRD. Although with lower frequency, $\mathrm{O}_{3}$ concentration and exceedance are also high under P8 and P9. This is mainly caused by the high temperature, abundant sunshine and subsidence air mass in the outskirt area of a tropical cyclone. In this regard, we group P1, P2, P4, P8 and P9 together and call them high- $\mathrm{O}_{3}$ patterns (HOPs).

It is discovered from Table 1 that $\mathrm{O}_{3}$ concentration and exceedance rate across synoptic patterns have a much higher correlation with occurrence frequency of $\mathrm{AS}\left(r^{2}=\right.$ 0.85 and $0.78, \mathrm{P}<0.05$ respectively) than that of $\mathrm{HW}$ and TI $\left(r^{2}=0.10\right.$ and $0.35, \mathrm{P}<0.8$ and $r^{2}=0.10$ and $-0.12, \mathrm{P}<$ 0.8 , respectively), which further confirms the fact that AS is the major driver for $\mathrm{O}_{3}$ pollution in the PRD. With the inter-pattern ranking of $\mathrm{O}_{3}$ levels and exceedance rates mainly determined by AS, $\mathrm{HW}$ can adjust $\mathrm{O}_{3}$ levels and 

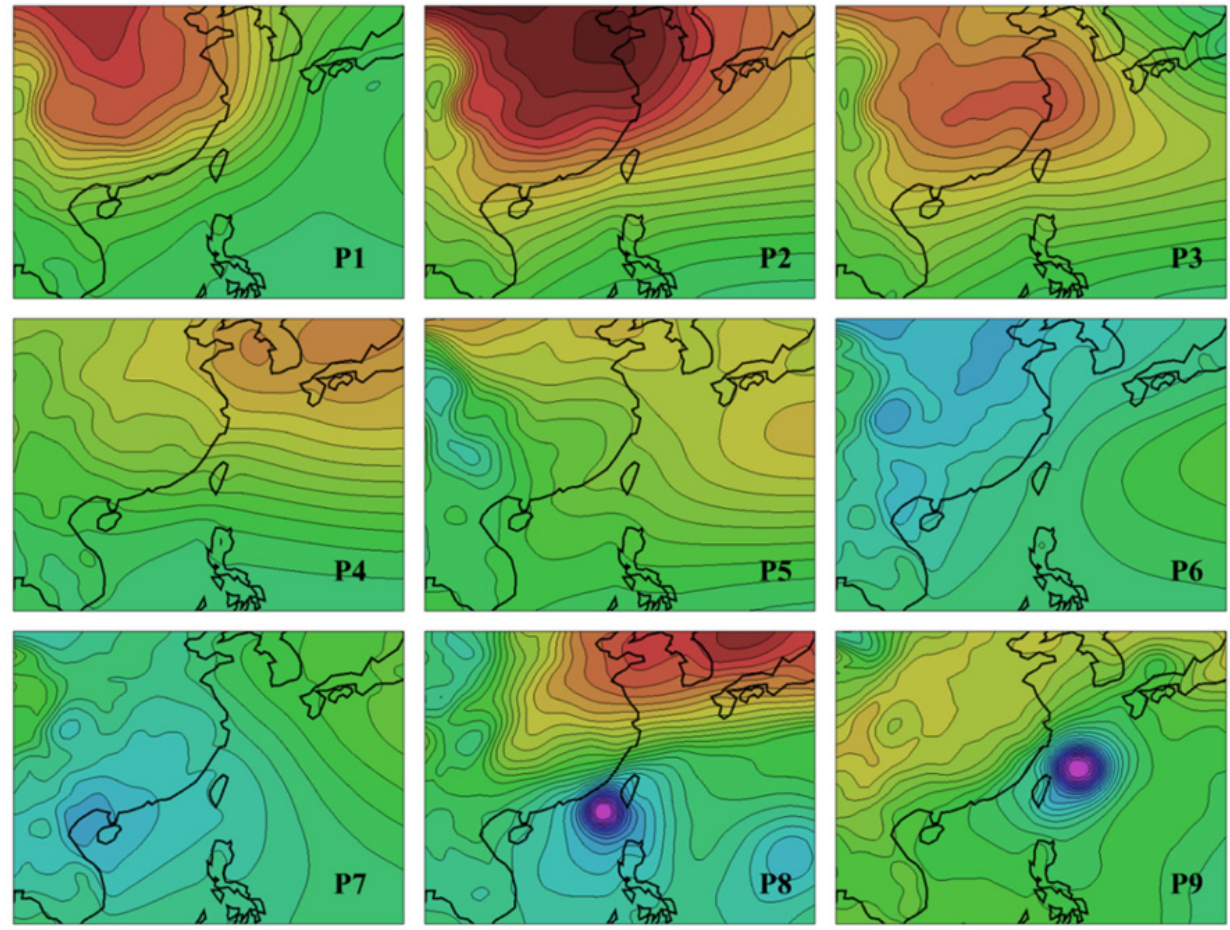

$\begin{array}{lllllllll}993 & 997 & 1001 & 1005 & 1009 & 1013 & 1017 & 1021 & 1025\end{array}$

Fig. 6. Nine predominant synoptic patterns identified by the averaged sea level pressure (hPa) fields during 1979-2017 and the semi-objective classification method.

Table 1. Occurrence frequencies of nine synoptic patterns and mean MDA8 $\mathrm{O}_{3}$ concentrations $\left(\mathrm{O}_{3 \mathrm{M}}\right)$ and occurrence frequencies of $\mathrm{O}_{3} \mathrm{X}, \mathrm{HW}, \mathrm{AS}$, TI under nine synoptic patterns during April-October 2006-2017.

\begin{tabular}{lllllll}
\hline Type & Frequency (\%) & $\mathrm{HW}(\%)$ & $\mathrm{AS}(\%)$ & $\mathrm{TI}(\%)$ & $\mathrm{O}_{3 \mathrm{M}}\left(\mu \mathrm{g} \mathrm{m}^{-3}\right)$ & $\mathrm{O}_{3} \mathrm{X}(\%)$ \\
\hline P1 & 10.8 & 14.3 & 28.8 & 10.8 & 117 & 15.7 \\
P2 & 10.6 & 3.5 & 34.0 & 24.5 & 110 & 13.1 \\
P3 & 4.4 & 1.5 & 11.3 & 23.2 & 92 & 6.7 \\
P4 & 10.8 & 13.1 & 21.6 & 10.8 & 100 & 8.2 \\
P5 & 4.5 & 4.8 & 12.0 & 16.2 & 80 & 3.2 \\
P6 & 31.8 & 26.8 & 10.9 & 3.1 & 74 & 4.5 \\
P7 & 19.8 & 25.9 & 9.5 & 1.7 & 87 & 8.1 \\
P8 & 4.3 & 14.4 & 24.2 & 11.4 & 113 & 13.5 \\
P9 & 3.0 & 44.0 & 22.2 & 1.2 & 115 & 17.0 \\
\hline
\end{tabular}

exceedance rates but to a lesser extent. This is evidenced by higher $\mathrm{O}_{3}$ levels and exceedance rates for $\mathrm{P} 1$ than $\mathrm{P} 2$ and for P9 than P8 due to higher HW frequency of P1 and P9.

We further examine the impact of different EMEs on $\mathrm{O}_{3}$ concentrations under nine synoptic patterns. Fig. 7 shows a comparison between probability density functions (PDFs) of daily MDA8 $\mathrm{O}_{3}$ between EMEs (red curve) and nonEMEs (black curve) over the PRD. The PDFs are smoother for P1-P7 as these synoptic patterns occur more frequently. Black curves for the three EMEs are similar for the same synoptic pattern, while red curves show obvious differences in shape and frequency. Red curves generally show two types of features in comparison with black curves: peak shift to the right and enhanced right tails. Peak shift to the right indicates elevation of $\mathrm{O}_{3}$ concentration under normal condition and enhanced right tails demonstrates higher occurrence of $\mathrm{O}_{3} \mathrm{X}$ events. For the five HOPs, HW shifts the peak for P8 and P9 while enhances right tails for all five synoptic patterns, AS shifts the peak and enhances right tails for all five synoptic patterns, while TI only shifts the peak for P8 and P9 and reduces both left and right tails. It is also discovered that AS results in the greatest difference between red and black curves, while the red curves for HW shows the longest right tails. This further confirms that AS is the major driver for $\mathrm{O}_{3}$ pollution in the PRD that contributes to $\mathrm{O}_{3}$ increase under all circumstances, while HW mainly assists in further strengthening the intensity of $\mathrm{O}_{3}$ pollution. For the tropical cyclone-induced $\mathrm{O}_{3}$ pollution, TI can increase $\mathrm{O}_{3}$ level to some extent, but cannot contribute to further increase $\mathrm{O}_{3}$ to higher level. This is mainly due to the break-up of TI due to the subsidence air mass in the outskirt of a tropical cyclone. 

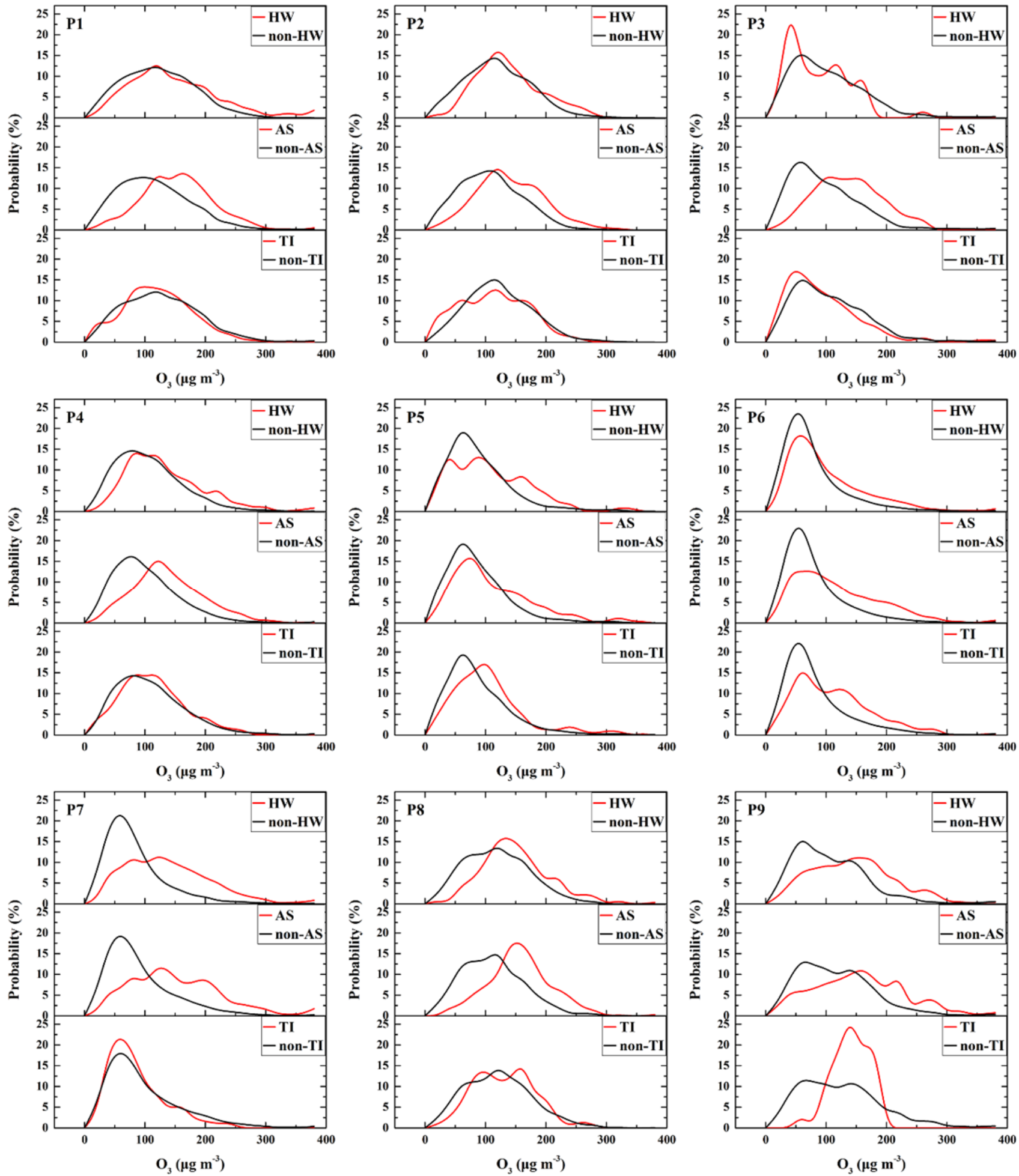

Fig. 7. Probability density functions of daily MDA8 $\mathrm{O}_{3}$ concentration for nine synoptic patterns during April-October 2006-2017. Red and black curves represent probability density functions during EMEs and non-EMEs, respectively.

To further elucidate the impact mechanism of EMEs on $\mathrm{O}_{3}$, we investigate the spatial distribution of changes in $\mathrm{O}_{3}$ concentration and exceedance rate during EMEs and nonEMEs under nine synoptic patterns, as shown in Figs. 8 and S6, respectively. It is clear that under different synoptic patterns, the impacting areas of EMEs on $\mathrm{O}_{3}$ concentration and exceedance are different. For the five HOPs, HW mainly affects $\mathrm{O}_{3}$ over northern and eastern PRD for P1, western for P4 and P9, and southern for P8. For P2, HW affects $\mathrm{O}_{3}$ concentration over western PRD, while its impact on $\mathrm{O}_{3}$ exceedance is mostly concentrated around $\mathrm{TH}$ station. Spatial distribution of HW impact for P1 is closest to that 
(a)
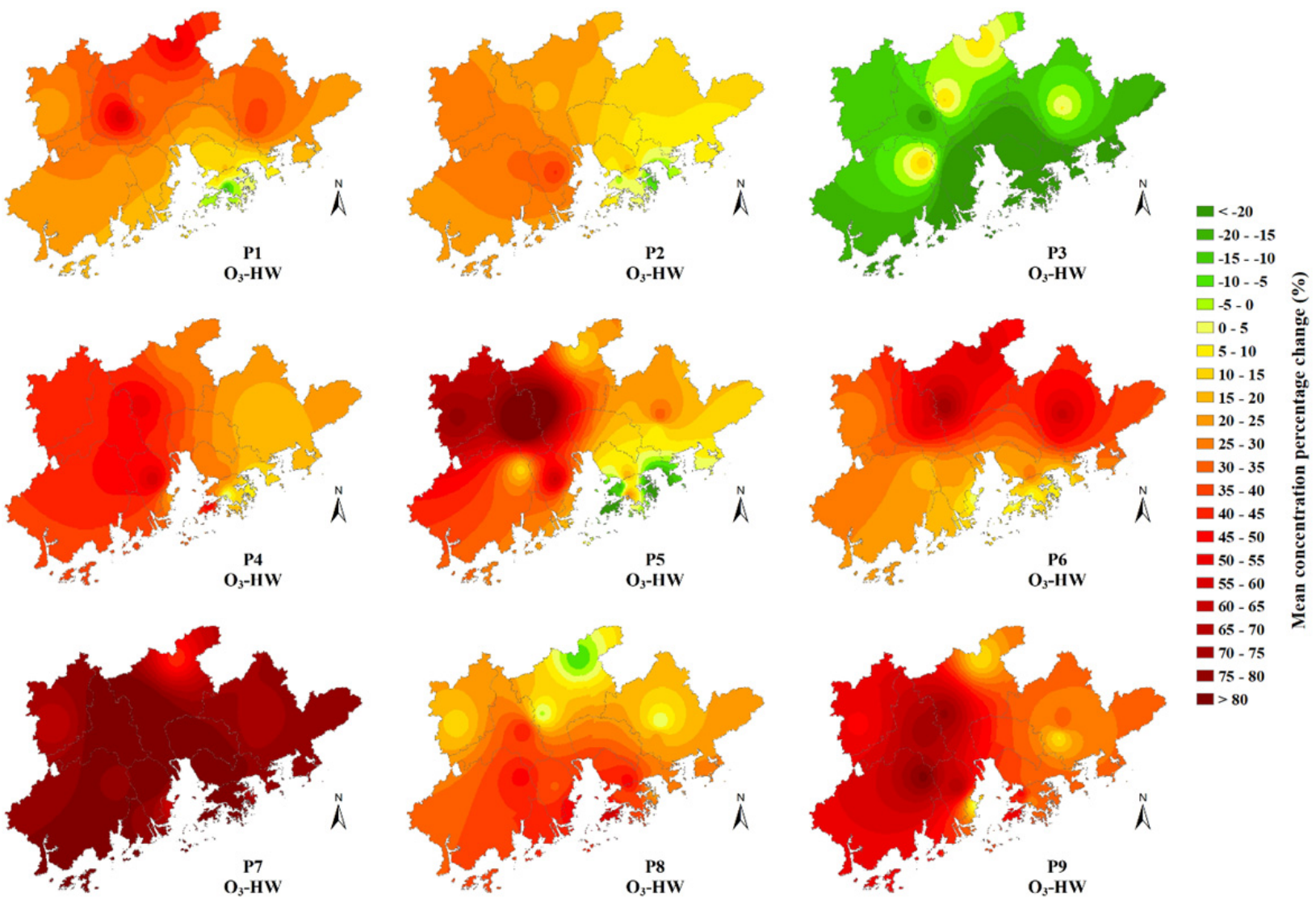

(b)
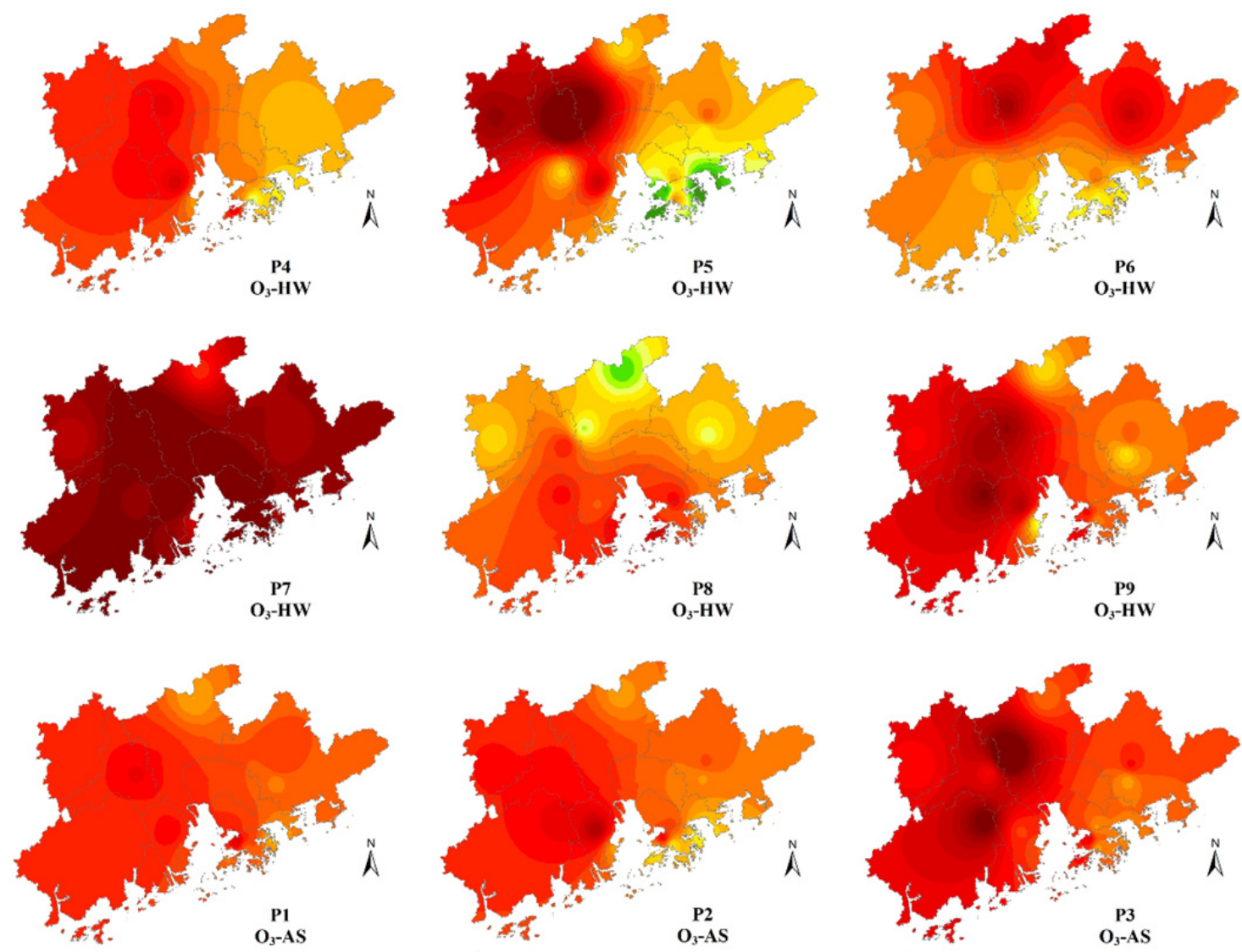

$\square<-20$
$-20--15$

- $-15--10$
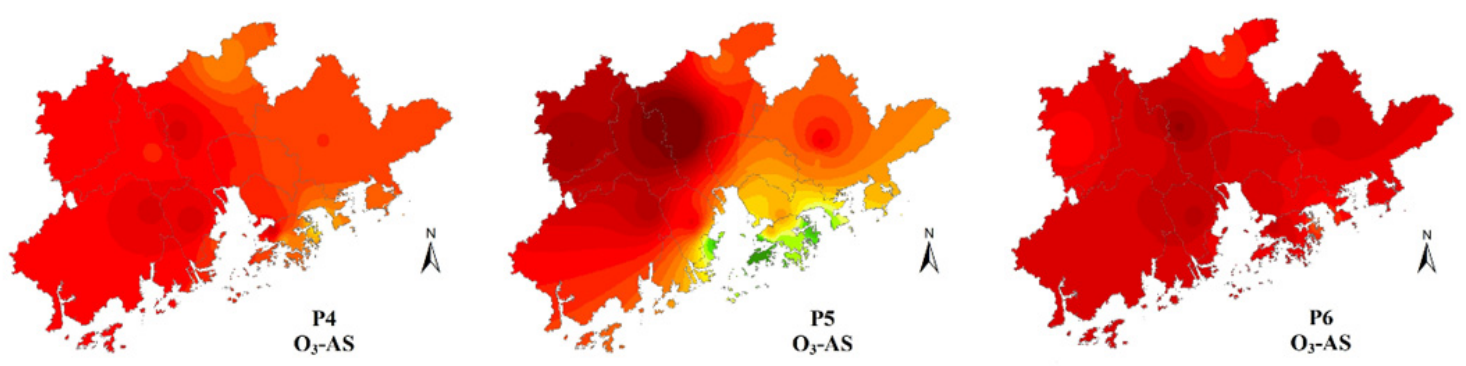

$\square-5-0$

$\square$ - 10

$\square 10-15$

$\square 15$ - 20

- 25 - 30

- $35-40$ 일

40 - 45
$\square 45-50$

$45-50$
$\square-50-55$

$55-60$
$60-65$
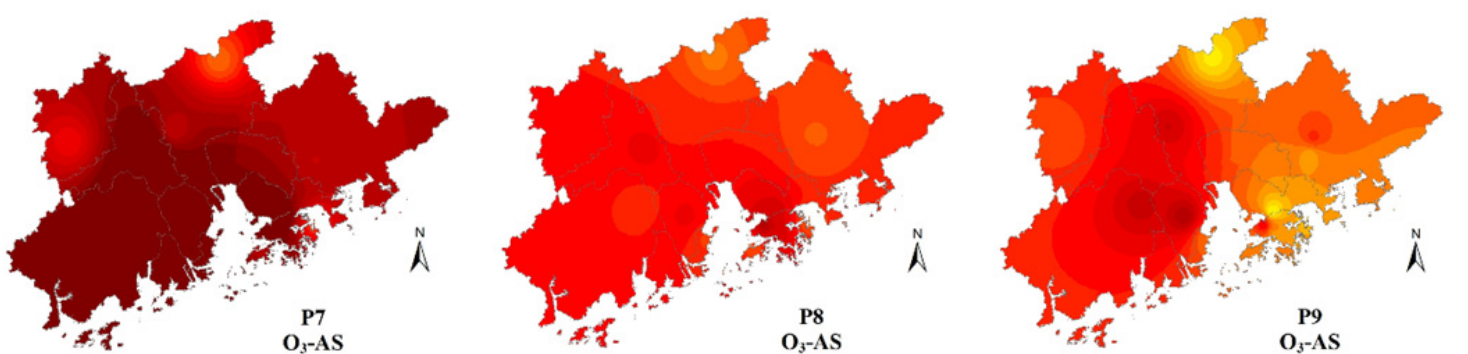

$-65-70$ >

- 70 - 75

$75-80$

Fig. 8. Percentage changes (\%) in MDA8 $\mathrm{O}_{3}$ concentration during (a) HW, (b) AS, and (c) TI with respect to non-EMEs conditions under nine synoptic patterns. 
(c)
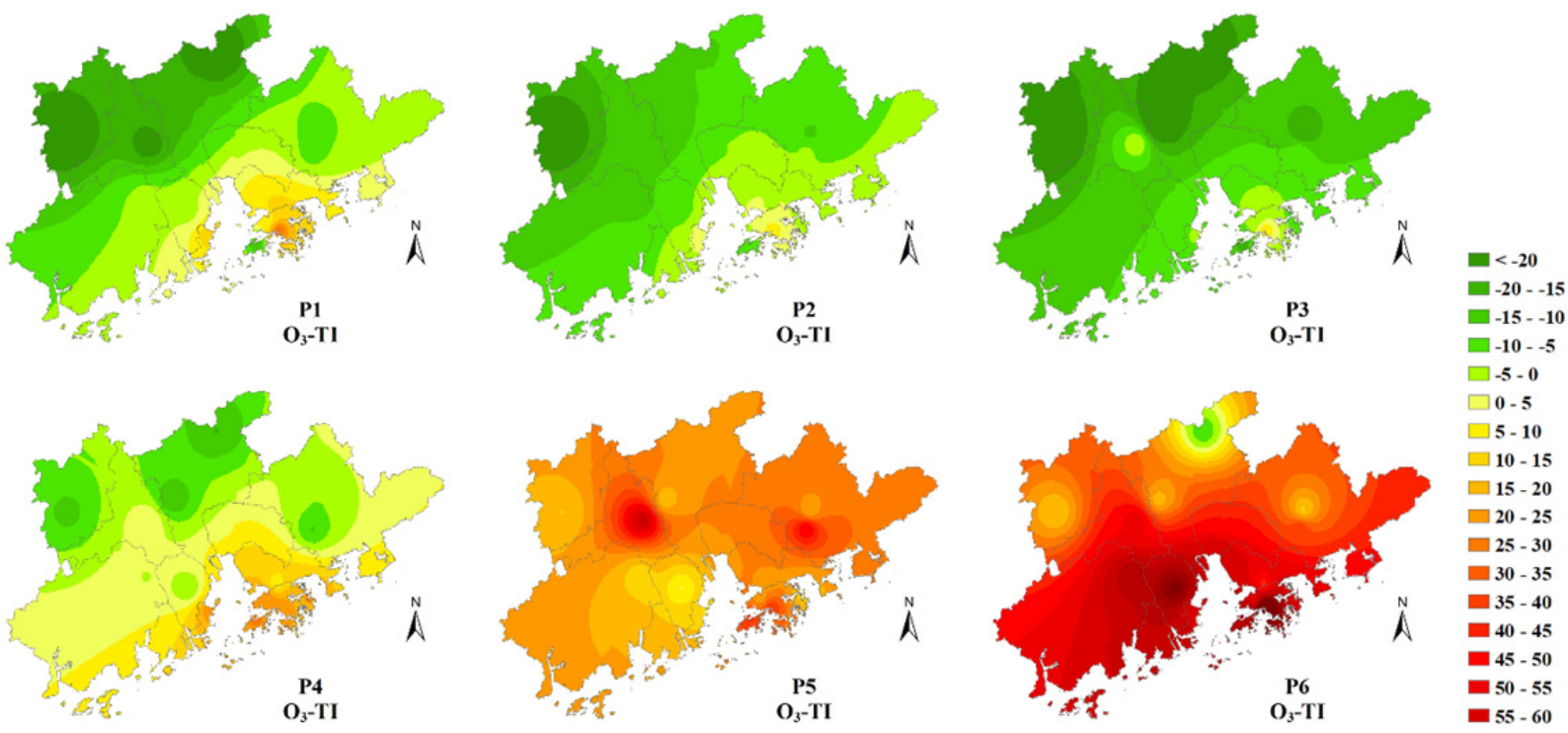

$-15--10$

$\square-10--5$

$\square-5-0$

$\square 0-5$

$\square$ - 10

$\square 10-15$

$\square-20$

$\square 20$ - 25

$\square 25$ - 30

무 30 - 35

마 -40

$40-45$

45 - 50

$50-55$
$-55-60$

- 60 - 65

$65-70$
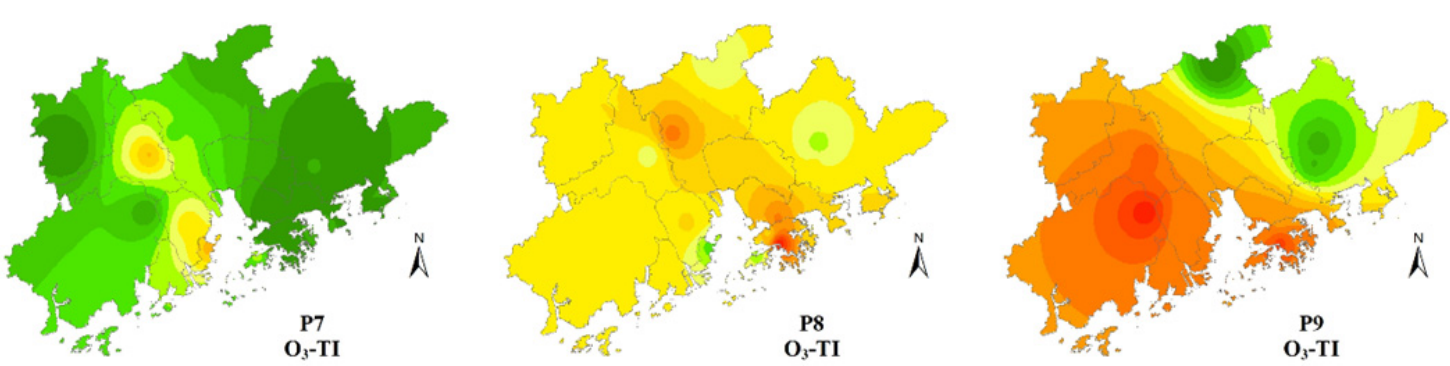

$70-75$

75 - 80

a $>80$

Fig. 8. (continued).

for the overall $\mathrm{O}_{3}$ concentration and exceedance (Figs. 3(a) and $3(\mathrm{e})$ ), indicating that $\mathrm{P} 1$ is the dominant synoptic pattern for $\mathrm{HW}$ impact on $\mathrm{O}_{3}$ for the PRD.

In comparison, AS poses relatively consistent impact on $\mathrm{O}_{3}$ concentration over the PRD with a slightly high area over western for $\mathrm{P} 2, \mathrm{P} 4$ and P9. Its impacts on $\mathrm{O}_{3}$ exceedance rates are more spatially variable and mainly concentrated on the western PRD. Spatial distributions of AS impact for P2, P4 and P9 are closest to that for the overall $\mathrm{O}_{3}$ concentration (Figs. 3(b) and 3(f)), indicating that they are the dominant synoptic patterns for AS impact on $\mathrm{O}_{3}$ for the PRD. It is also noticed that both $\mathrm{HW}$ and AS result in the greatest increases in $\mathrm{O}_{3}$ concentration (79.6 and $77.0 \%$ ) and exceedance rate (5.7 and 6.5 times) for P7, especially over southwestern PRD, suggesting that although $\mathrm{O}_{3}$ concentration and exceedance rate are relatively lower when PRD is controlled by a low pressure system over the Gulf of Tonkin, they can be greatly enhanced if EMEs occur.

The impact of TI on $\mathrm{O}_{3}$ concentration and exceedance rate shows a spatial contrast for all HOPs. Positive impacts on $\mathrm{O}_{3}$ concentration are mainly discovered for P8 and P9, the two tropical cyclone-related synoptic patterns. However, the impacts on $\mathrm{O}_{3}$ exceedance rates for these two patterns are significantly lower. This echoes our previous findings that TI cannot contribute to the build-up of $\mathrm{O}_{3}$ to a higher level due to the subsidence air mass that breaks up TI in the outskirt of a tropical cyclone. Spatial distributions of
TI impact for P1, P2 and P4 are closest to that for the overall $\mathrm{O}_{3}$ concentration (Fig. 3(c)), indicating that these Siberian high-related synoptic pattern contribute the most to TI impact on $\mathrm{O}_{3}$ concentration for the PRD. Although TI results in the greatest increase in $\mathrm{O}_{3}$ concentration and exceedance rate for $\mathrm{P} 6$, its occurrence frequency is very low $(3.1 \%)$ therefore would pose little impact on the overall $\mathrm{O}_{3}$ pollution level. All three EMEs poses higher impacts on the western side of the PRD, indicating western PRD is the area where $\mathrm{O}_{3}$ pollution is the most sensitive to EMEs.

\section{Long-term Trends of Impact of EMEs on MDA8 Ozone}

As shown in Fig. S7, $\mathrm{O}_{3}$ concentration is fluctuatedly increasing over the PRD. In this section, we examine whether the occurrence of EMEs acts as one of the driving factors for $\mathrm{O}_{3}$ increase. Fig. 9 illustrates the PDFs of daily MDA8 $\mathrm{O}_{3}$ during $\mathrm{HW}$ (red curve) and non-HW (black curve) over the PRD under nine synoptic patterns during four three-year periods, i.e., 2006-08, 2009-11, 2012-14 and 2015-17, and Fig. S8 shows the counterparts for AS and TI. It is noted that for all synoptic patterns, black curves do not show much difference as time evolves. In contrast, red curves show two types of features: peak shift to the right and enhanced right tails. As discussed previously, peak shift to the right indicates elevation of $\mathrm{O}_{3}$ concentration under normal condition and enhanced right tails demonstrates higher occurrence of $\mathrm{O}_{3} \mathrm{X}$ events. Shifts of HW red curves are more pronounced in $\mathrm{P} 2 / \mathrm{P} 5 / \mathrm{P} 7-\mathrm{P} 9$, 

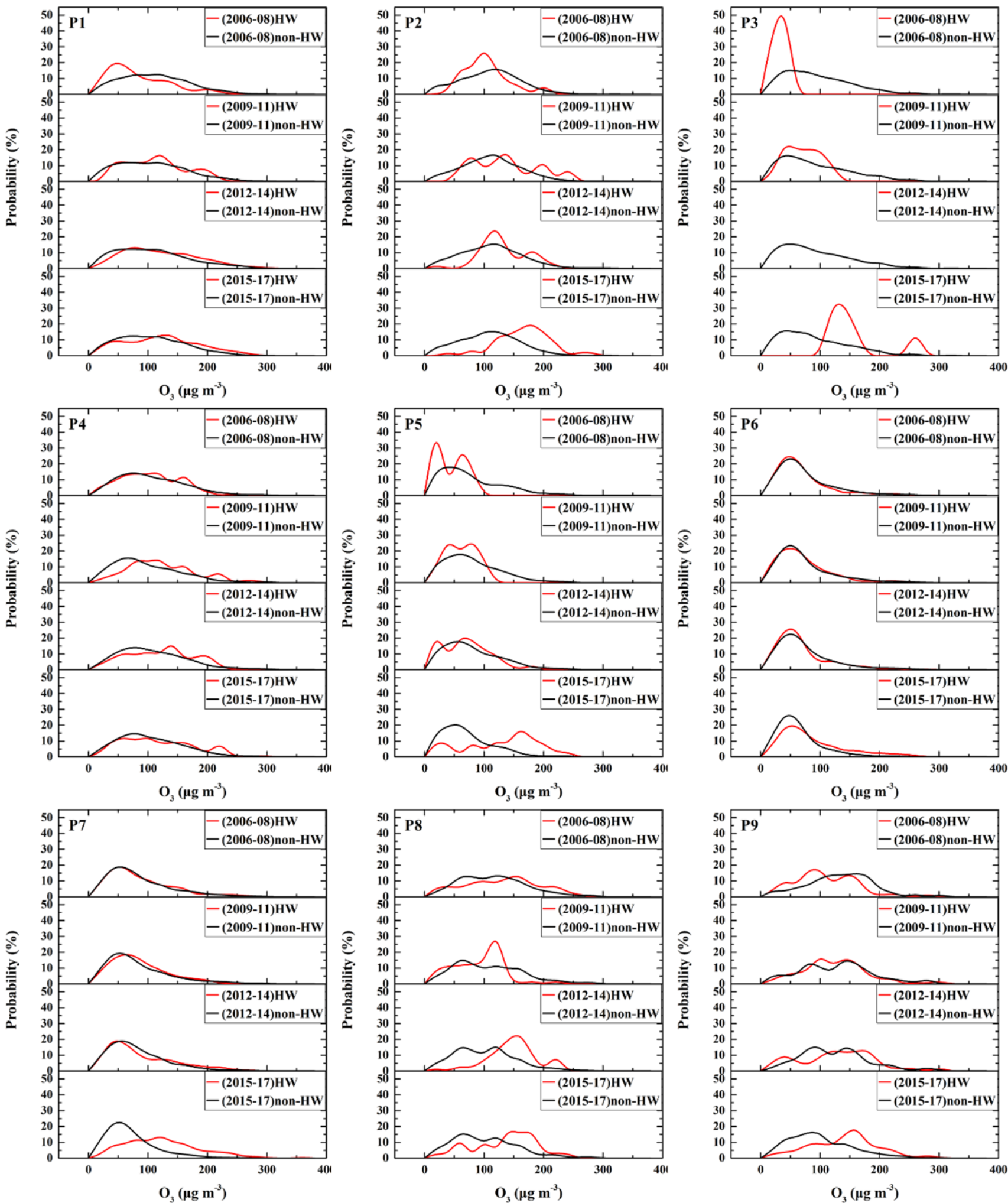

Fig. 9. Probability density functions of daily $\mathrm{MDA} 8 \mathrm{O}_{3}$ concentration for nine synoptic patterns during 2006-08, 2009-11, 2012-14 and 2015-17. Red and black curves represent probability density functions during HW and non-HW, respectively.

while enhanced right tails are more obvious in P1/P2/P5-7. Considering that $\mathrm{P} 1$ is the dominant synoptic pattern for $\mathrm{HW}$ impact, the increasing occurrence of $\mathrm{O}_{3} \mathrm{X}$ events by HW when PRD is controlled by Siberian high is one of the main reasons for $\mathrm{O}_{3}$ increase. Shifts of AS red curves are greater in P1/P6-9, while enhanced right tails are more obvious in $\mathrm{P} 2 / \mathrm{P} 4 / \mathrm{P} 6-\mathrm{P} 8$. Considering $\mathrm{P} 2 / \mathrm{P} 4 / \mathrm{P} 9$ are dominant synoptic patterns for AS impact, elevation of $\mathrm{O}_{3}$ level by 
AS when PRD is controlled by Siberian high and the increasing occurrence of $\mathrm{O}_{3}$ pollution events by AS when PRD is located at the outskirt of a tropical cyclone play a leading role to the $\mathrm{O}_{3}$ increase. Shifts of TI red curves are greater in $\mathrm{P} 1 / \mathrm{P} 4 / \mathrm{P} 6 / \mathrm{P} 8$ and right tails are more enhanced in $\mathrm{P} 6-\mathrm{P} 8$. Considering $\mathrm{P} 1 / \mathrm{P} 2 / \mathrm{P} 4$ are dominant synoptic patterns for TI impact, elevation of $\mathrm{O}_{3}$ by TI when PRD is controlled by Siberian high also contributes to $\mathrm{O}_{3}$ increase, especially in southern PRD. It is also noticed that the most significant peak shift and right tail enhancement happen during 2015-17, suggesting that the impact of EMEs on $\mathrm{O}_{3}$ becomes increasingly prominent.

There are two main reasons responsible for the increasing impact of EMEs on $\mathrm{O}_{3}$ over the PRD. First, emission of $\mathrm{O}_{3}$ precursors has changed greatly over the twelve-year period. In response to the stringent control measures which is preferentially targeted to reduce ambient $\mathrm{PM}_{2.5}$ concentration, $\mathrm{NO}_{\mathrm{x}}$ emissions have been reduced by $20 \%$ while VOCs emissions are still in an increasing trend. Most $\mathrm{NO}_{\mathrm{x}}$ emission reduction happens during 2015-17. The inadequate regulation on VOCs emissions as well as unbalanced $\mathrm{NO}_{\mathrm{x}}$ reduction most likely result in $\mathrm{O}_{3}$ increase (Wang et al., 2016a). Second, the degree of EMEs may be intensified in response to climate change (Horton et al., 2014; Meehl et $a l ., 2018)$. Studies have shown that with ongoing increases in greenhouse gas emissions, corresponding global warming are projected to increase the intensity and persistence of EMEs throughout the majority of the tropics and subtropics, which are expected to alter the build-up and dispersion of pollutant. The increase in the frequency of tropical cyclones may be another factor leading to $\mathrm{O}_{3}$ increase during 201517. The frequency of P8 increases from 3.6\% during 200614 to $6.4 \%$ during $2015-17$ while that of P9 increases from $2.7 \%$ during $2006-14$ to $4.0 \%$ during $2015-17$.

\section{CONCLUSIONS}

We examine the impacts of EMEs on $\mathrm{O}_{3}$ concentration and exceedance rate during April-October, 2006-2017 over the PRD region of China. In general, HW, AS and TI favor $\mathrm{O}_{3}$ formation and accumulation but with a significant regional heterogeneity. Discrepancy is also found between spatial distribution of EMEs and their impacts on $\mathrm{O}_{3}$, which is mainly caused by the spatial heterogeneity in emissions of $\mathrm{O}_{3}$ precursors. HW and AS function over different areas to increase $\mathrm{O}_{3}$, making concurrence of $\mathrm{HW}$ and $\mathrm{AS}$ unable to elevate $\mathrm{O}_{3}$ into a higher level. In general, $\mathrm{O}_{3} \mathrm{X}$ events are largely initiated by HW and AS which favor the formation and build-up of $\mathrm{O}_{3}$, while $\mathrm{O}_{3} \mathrm{X}$ events are maintained mostly by persistent $\mathrm{AS}$ and TI. HW also assists in maintaining $\mathrm{O}_{3} \mathrm{X}$ events in the northeastern PRD.

The impacts under different temperature ranges and meso-scale synoptic patterns are further investigated to elucidate the roles of EMEs in modulating $\mathrm{O}_{3}$ concentration. When temperature is above $304 \mathrm{~K}, \mathrm{O}_{3}$ concentration does not change much along with the extension of high temperature days. The effect of $\mathrm{AS}$ on $\mathrm{O}_{3}$ concentration is similar as $10 \mathrm{~K}$ temperature increase during non-AS days, while the effect of AS and TI on $\mathrm{O}_{3}$ exceedance is comparable with $6 \mathrm{~K}$ temperature increase during non-EMEs condition.

The inter-pattern ranking of $\mathrm{O}_{3}$ levels and exceedance rates are mostly similar to that of AS, suggesting $\mathrm{AS}$ is the main driving factor for $\mathrm{O}_{3}$ pollution in the PRD while $\mathrm{HW}$ adjusts $\mathrm{O}_{3}$ levels and exceedance rates but to a lesser extent. $\mathrm{P} 1$ is the dominant synoptic pattern for $\mathrm{HW}$ impact on $\mathrm{O}_{3}$ for the PRD while $\mathrm{P} 2 / \mathrm{P} 4 / \mathrm{P} 9$ and $\mathrm{P} 1 / \mathrm{P} 2 / \mathrm{P} 4$ are dominant patterns for AS and TI impacts, respectively. This highlights that Siberian high and the approaching of a tropical cyclone are the two large-scale circulations during which EMEs pose the largest impact on $\mathrm{O}_{3}$ pollution in the PRD. The impact of EMEs on $\mathrm{O}_{3}$ becomes increasingly prominent during 2015-17, due possibly to the undesirable reduction ratio of VOCs and $\mathrm{NO}_{\mathrm{x}}$ and the intensified EMEs due to climate change. Increase in the frequency of tropical cyclone may also pose an important role in $\mathrm{O}_{3}$ increase.

It is noted that the reanalyzed wind speed at $\mathrm{HKO}$ is higher than observations and the reanalyzed temperature at GZ-BY is lower than observations. This highlights that $\mathrm{HW}$ and AS frequencies at certain areas in the PRD may be underestimated. The impact of HW and AS impact on $\mathrm{O}_{3}$ would be overestimated. As one of the most industrialized and urbanized areas in China, PRD is concentrated with a variety of VOCs and $\mathrm{NO}_{\mathrm{x}}$ emission sources. We have identified that during EMEs and non-EMEs, $\mathrm{O}_{3}$ pollution characteristics over the PRD is different in terms of spatial distribution and formation mechanism. Therefore, it is essential to formulate location-specific $\mathrm{O}_{3}$ control measures targeting on normal conditions and $\mathrm{O}_{3}$ pollution events separately. We have also highlighted in this study that $\mathrm{O}_{3}$ pollution events in the PRD is largely triggered by EMEs. With the current weather forecast technology, it is feasible to accurately forecast EMEs 48-72 hours before their occurrences, giving policy-makers enough time to implement contingency control measures to reduce peak levels during $\mathrm{O}_{3}$ pollution events over different areas of the PRD.

\section{ACKNOWLEDGMENTS}

This research is supported by National Natural Science Foundation of China (No. 91644221). The authors are grateful to Guangdong Environmental Monitoring Center and Hong Kong Environmental Protection Department for providing $\mathrm{O}_{3}$ monitoring data used in this study. The authors are also thank the Key Laboratory of Pollution Control and Ecosystem Restoration in Industry Clusters (Ministry of Education) and the State Key Laboratory of Multi-phase Complex Systems.

\section{SUPPLEMENTARY MATERIAL}

Supplementary data associated with this article can be found in the online version at http://www.aaqr.org.

\section{REFERENCE}

Banta, R.M., Senff, C.J., White, A.B., Trainer, M., Mcnider, R.T., Valente, R.J., Mayor, S.D., Alvarez, R.J., Hardesty, R.M. and Parrish, D. (1998). Daytime buildup and 
nighttime transport of urban ozone in the boundary layer during a stagnation episode. J. Geophys. Res. 103: 22519-22544.

Barry, R.G. and Kiladis, G. (1981). Synoptic climatology of the Western United States in relation to climatic fluctuations during the twentieth century. J. Climatol. 1: 97-113.

Black, E., Blackburn, M., Harrison, G., Hoskins, B. and Methven, J. (2010). Factors contributing to the summer 2003 European heat wave. Weather 59: 217-223.

Chang, K.L., Petropavlovskikh, I., Copper, O.R., Schultz, M.G. and Wang, T. (2017). Regional trend analysis of surface ozone observations from monitoring networks in eastern North America, Europe and East Asia. Elem. Sci. Anth. 5: 50.

Cheng, L., Wang, S., Gong, Z., Li, H., Yang, Q. and Wang, Y. (2018). Regionalization based on spatial and seasonal variation in ground-level ozone concentrations across China. J. Environ. Sci. (China) 67: 179-190.

Derwent, R.G., Manning, A.J., Simmonds, P.G., Spain, T.G. and O'Doherty, S. (2018). Long-term trends in ozone in baseline and European regionally-polluted air at Mace Head, Ireland over a 30-year period. Atmos. Environ. 179: 279-287.

Du, W., Hong, Y., Xiao, H., Zhang, Y., Chen, Y., Xu, L., Chen, J. and Deng, J. (2017). Chemical characterization and source apportionment of $\mathrm{PM}_{2.5}$ during spring and winter in the Yangtze River Delta, China. Aerosol Air Qual. Res. 17: 2165-2180.

El-Kadi, A.K.A. and Smithson, P.A. (1992). Atmospheric classifications and synoptic climatology. Prog. Phys. Geogr. 16: 432-455.

Fiore, A.M., Naik, V. and Leibensperger, E.M. (2015). Air quality and climate connections. J. Air Waste Manage. Assoc. 65: 645-685.

Fontes, T., Li, P., Barros, N. and Zhao, P. (2017). Trends of $\mathrm{PM}_{2.5}$ concentrations in China: A long term approach. J. Environ. Manage. 196: 719-732.

Garrido-Perez, J.M., Ordonez, C., Garcia-Herrera, R. and Barriopedro, D. (2018). Air stagnation in Europe: Spatiotemporal variability and impact on air quality. Sci. Total Environ. 645: 1238-1252.

Heywood, G.S.P., M.A and B.Sc (1953). Surface pressurepatterns and weather around the year in Hong Kong. Royal Observatory Technical Memoir. No.6.

Horton, D.E., Skinner, C.B., Singh, D. and Diffenbaugh, N.S. (2014). Occurrence and persistence of future atmospheric stagnation events. Nat. Clim. Change 4: 698-703.

Hou, P. and Wu, S. (2016). Long-term changes in extreme air pollution meteorology and the implications for air quality. Sci. Rep. 6: 23792.

Hou, X., Wang, Y. and Li, X. (2018). The chemical and physical processes of ambient ozone simulated by a photochemical air quality modeling system in urban and rural areas in the Pearl River Delta region, China. Atmos. Pollut. Res. S130910421730613X.

Huang, J.P., Fung, J.C.H. and Lau, A.K.H. (2006). Integrated processes analysis and systematic meteorological classification of ozone episodes in Hong Kong. $J$. Geophys. Res. 111: D20309.

Im, U., Markakis, K., Poupkou, A., Melas, D., Unal, A., Gerasopoulos, E., Daskalakis, N., Kindap, T. and Kanakidou, M. (2011). The impact of temperature changes on summer time ozone and its precursors in the Eastern Mediterranean. Atmos. Chem. Phys. 11: 3847-3864.

IPCC (2014). Climate change 2014 synthesis report. Environmental Policy Collection. 27: 408.

Jacob, D.J. and Winner, D.A. (2009). Effect of climate change on air quality. Atmos. Environ. 43: 51-63.

Ke, L., Jacob, D.J., Liao, H., Shen, L. and Bates, K.H. (2019). Anthropogenic drivers of 2013-2017 trends in summer surface ozone in China. Proc. Natl. Acad. Sci. U.S.A. 116: 422-427.

Kirchhofer, W. (1973). Classification of European $500 \mathrm{mb}$ patterns. Swiss Meteorological Institute. Zurich. Switzerland. No. 43.

Lam, Y.F., Cheung, H.M. and Ying, C.C. (2018). Impact of tropical cyclone track change on regional air quality. Sci. Total Environ. 610-611: 1347-1355.

Lei, R., Talbot, R., Wang, Y., Wang, S.C. and Estes, M. (2018). Influence of cold fronts on variability of daily surface $\mathrm{O}_{3}$ over the Houston-Galveston-Brazoria area in Texas, USA during 2003-2016. Atmosphere 9: 159.

Leibensperger, E.M., Mickley, L.J. and Jacob, D.J. (2008). Sensitivity of US air quality to mid-latitude cyclone frequency and implications of 1980-2006 climate change. Atmos. Chem. Phys. 8: 7075-7086.

Li, G., Bei, N., Cao, J., Wu, J., Long, X., Feng, T., Dai, W., Liu, S., Zhang, Q. and Tie, X. (2017). Widespread and persistent ozone pollution in eastern China during the non-winter season of 2015: Observations and source attributions. Atmos. Chem. Phys. 17: 1-39.

Liao, T., Gui, K., Jiang, W., Wang, S., Wang, B., Zeng, Z., Che, H., Wang, Y. and Sun, Y. (2018). Air stagnation and its impact on air quality during winter in Sichuan and Chongqing, southwestern China. Sci. Total Environ. 635: 576-585.

Lin, Y., Zou, J., Yang, W. and Li, C.Q. (2018). A review of recent advances in research on $\mathrm{PM}_{2.5}$ in China. Int. $J$. Environ. Res. Public Health 15: 438.

McGlynn, D., Mao, H., Sive, B. and Sharac, T. (2018). Understanding long-term variations in surface ozone in United States (U.S.) national parks. Atmosphere 9: 125.

Meehl, G.A., Tebaldi, C., Tilmes, S., Lamarque, J.F., Bates, S., Pendergrass, A. and Lombardozzi, D. (2018). Future heat waves and surface ozone. Environ. Res. Lett. 13: 064004.

Moritz, R. (1979). Synoptic climatology of the Beaufort Sea Coast of Alaska. Institute of Arctic \& Alpine Research, University of Colorado. p. 176.

Ngan, F. and Byun, D. (2011). Classification of weather patterns and associated trajectories of high-ozone episodes in the Houston-Galveston-Brazoria area during the 2005/06 TexAQS-II. J. Appl. Meteorol. Clim. 50: 485-499.

Oozeer, M.Y. (2016). Numerical study of the transport and convective mechanisms of biomass burning haze in SouthSoutheast Asia. Aerosol Air Qual. Res. 16: 2950-2963. 
Ou, J., Zheng, J., Li, R., Huang, X., Zhong, Z., Zhong, L. and Lin, H. (2015). Speciated OVOC and VOC emission inventories and their implications for reactivity-based ozone control strategy in the Pearl River Delta region, China. Sci. Total Environ. 530-531: 393-402.

Ou, J., Yuan, Z., Zheng, J., Huang, Z., Shao, M., Li, Z., Huang, X., Guo, H. and Louie, P.K. (2016). Ambient ozone control in a photochemically active region: Shortterm despiking or long-term attainment? Environ. Sci. Technol. 50: 5720-5728.

Ozelkan, E., Bagis, S., Ozelkan, E.C., Ustundag, B.B., Yucel, M. and Ormeci, C. (2015). Spatial interpolation of climatic variables using land surface temperature and modified inverse distance weighting. Int. J. Remote. Sens. 36: 1000-1025.

Porter, W.C., Heald, C.L., Cooley, D. and Russell, B. (2015). Investigating the observed sensitivities of airquality extremes to meteorological drivers via quantile regression. Atmos. Chem. Phys. 15: 10349-10366.

Pu, X., Wang, T.J., Huang, X., Melas, D., Zanis, P., Papanastasiou, D.K. and Poupkou, A. (2017). Enhanced surface ozone during the heat wave of 2013 in Yangtze River Delta region, China. Sci. Total Environ. 603-604: 807-816.

Robinson, P.J. (2001). On the definition of a heat wave. $J$. Appl. Meteorol. 40: 762-775.

Schnell, J.L. and Prather, M.J. (2017). Co-occurrence of extremes in surface ozone, particulate matter, and temperature over eastern North America. Proc. Natl. Acad. Sci. U.S.A. 114: 2854-2859.

Shu, L., Xie, M., Gao, D., Wang, T., Fang, D., Liu, Q., Huang, A. and Peng, L. (2017). Regional severe particle pollution and its association with synoptic weather patterns in the Yangtze River Delta region, China. Atmos. Chem. Phys. 17: 12871-12891.

Solberg, S., Hov, Ø., Søvde, A., Isaksen, I.S.A., Coddeville, P., De Backer, H., Forster, C., Orsolini, Y. and Uhse, K. (2008). European surface ozone in the extreme summer 2003. J. Geophys. Res. 113: D07307.

Son, J.Y., Lee, J.T., Anderson, G.B. and Bell, M.L. (2012). The impact of heat waves on mortality in seven major cities in Korea. Environ. Health Perspect. 120: 566571.

Steiner, A.L., Davis, A.J., Sillman, S., Owen, R.C., Michalak, A.M. and Fiore, A.M. (2010). Observed suppression of ozone formation at extremely high temperatures due to chemical and biophysical feedbacks. Proc. Natl. Acad. Sci. U.S.A. 107: 19685-19690.

Sun, W., Hess, P. and Liu, C. (2017). The impact of meteorological persistence on the distribution and extremes of ozone. Geophys. Res. Lett. 44: 1545-1553.

Theoharatos, G., Pantavou, K., Mavrakis, A., Spanou, A., Katavoutas, G., Efstathiou, P., Mpekas, P. and Asimakopoulos, D. (2010). Heat waves observed in 2007 in Athens, Greece: Synoptic conditions, bioclimatological assessment, air quality levels and health effects. Environ. Res. 110: 152-161.

Tong, C.H.M., Yim, S.H.L., Rothenberg, D., Wang, C., Lin, C.Y., Chen, Y.D. and Lau, N.C. (2018). Assessing the impacts of seasonal and vertical atmospheric conditions on air quality over the Pearl River Delta region. Atmos. Environ. 180: 69-78.

Wang, N., Lyu, X.P., Deng, X.J., Guo, H., Deng, T., Li, Y., Yin, C.Q., Li, F. and Wang, S.Q. (2016a). Assessment of regional air quality resulting from emission control in the Pearl River Delta region, southern China. Sci. Total Environ. 573: 1554-1565.

Wang, T., Xue, L., Brimblecombe, P., Lam, Y.F., Li, L. and Zhang, L. (2017a). Ozone pollution in China: A review of concentrations, meteorological influences, chemical precursors, and effects. Sci. Total Environ. 575: 1582-1596.

Wang, W., Wen, Z., Li, X., Xin, W. and Wang, D. (2016b). Synoptic-scale characteristics and atmospheric controls of summer heat waves in China. Clim. Dyn. 46: 2923-2941.

Wang, W.N., Cheng, T.H., Gu, X.F., Chen, H., Guo, H., Wang, Y., Bao, F.W., Shi, S.Y., Xu, B.R., Zuo, X., Meng, C. and Zhang, X.C. (2017b). Assessing spatial and temporal patterns of observed ground-level ozone in China. Sci. Rep. 7: 3651.

World Meteorological Organization (2015). Heatwaves and health: Guidance on warning-system development. World Meteorological Organization, Geneva, Switzerland.

Wu, J.B., Wang, Q., Chen, H., Zhang, Y. and Wild, O. (2017). On the origin of surface ozone episode in Shanghai over Yangtze River Delta during a prolonged heat wave. Aerosol Air Qual. Res. 17: 2804-2815.

Zhai, P. and Pan, X. (2003). Trends in temperature extremes during 1951-1999 in China. Geophys. Res. Lett. 30: 1913.

Zhang, J., Gao, Y., Luo, K., Leung, L.R., Zhang, Y., Wang, K. and Fan, J. (2018a). Impacts of compound extreme weather events on ozone in the present and future. Atmos. Chem. Phys. 18: 9861-9877.

Zhang, Y., Cooper, O.R., Gaudel, A., Thompson, A.M., Nédélec, P., Ogino, S.Y. and West, J.J. (2016a). Tropospheric ozone change from 1980 to 2010 dominated by equatorward redistribution of emissions. Nat. Geosci. 9: 875-879.

Zhang, Y., Mao, H., Ding, A., Zhou, D. and Fu, C. (2013). Impact of synoptic weather patterns on spatio-temporal variation in surface $\mathrm{O}_{3}$ levels in Hong Kong during 1999-2011. Atmos. Environ. 73: 41-50.

Zhang, Y., Ding, A., Mao, H., Nie, W., Zhou, D., Liu, L., Huang, X. and Fu, C. (2016b). Impact of synoptic weather patterns and inter-decadal climate variability on air quality in the North China Plain during 1980-2013. Atmos. Environ. 124: 119-128.

Zhang, Z., Zhang, X., Gong, D., Kim, S.J., Mao, R. and Zhao, X. (2016c). Possible influence of atmospheric circulations on winter haze pollution in the BeijingTianjin-Hebei region, northern China. Atmos. Chem. Phys. 15: 22493-22526.

Zhang, Z., Ma, Z. and Kim, S.J. (2018b). Significant decrease of $\mathrm{PM}_{2.5}$ in Beijing based on long-term records and Kolmogorov-Zurbenko filter approach. Aerosol Air Qual. Res. 18: 711-718. 
Zhu, J. and Liang, X.Z. (2013). Impacts of the Bermuda High on regional climate and ozone over the United States. J. Clim. 26: 1018-1032.
Received for review, January 17, 2019

Revised, April 19, 2019

Accepted, May 18, 2019 